\title{
Time-dependent behaviour of sand with different fine contents under oedometric loading
}

\author{
Friedrich Levin, Stefan Vogt, and Roberto Cudmani
}

\begin{abstract}
To characterize the effects of creep, strain rate, and relaxation in granular soils, different sands have been studied under oedometric loading. The tests were analysed in the framework of the isotache concept. The results show increasing creep rates with increasing vertical stresses and a strong reduction of the creep rate upon unloading. A lower void ratio leads to less creep. Evaluation of the ratio $C_{\alpha} / C_{\mathrm{c}}$, where $C_{\alpha}$ is the creep coefficient and $C_{\mathrm{c}}$ is the compression index, demonstrates considerable deviation from a constant soil-specific value for the sands. With increasing fine content, however, a constant soil-specific ratio has been found for a silty sand. In strain rate-controlled tests, a sand with low and a sand with significant content of nonplastic fines were compared. Constant rate of strain tests displayed practically no strain rate dependency for the sand with little fines and a well visible strain rate dependency for the very silty sand. Tests with stepwise change of strain rate showed non-isotache behaviour for the sand with little fines and isotache behaviour for the other. Stress-relaxation tests displayed an isochronous behaviour. The analysis of the three viscous effects in sands showed they cannot altogether be mathematically described in the framework of the isotache concept. A new compression model for the creep behaviour of sands is presented.
\end{abstract}

Key words: sand, viscosity, creep, rate dependency, stress relaxation.

Résumé : Pour caractériser les effets du fluage, de la vitesse de déformation et de la relaxation dans les sols granulaires, différents sables ont été étudiés sous chargement œdométrique. Les essais ont été analysés dans le cadre du concept d’isotache. Les résultats montrent des taux de fluage croissants avec des contraintes verticales croissantes et une forte réduction du taux de fluage lors du déchargement. Un indice de vide plus faible entraîne moins de fluage. L'évaluation du ratio $C_{\alpha} / C_{\mathrm{c}}$, où $C_{\alpha}$ est le coefficient de fluage et $C_{\mathrm{c}}$ est l'indice de compression, prouve qu'il y a un écart considérable par rapport à une valeur constante spécifique au sol pour les sables. Cependant, avec l'augmentation de la teneur en fines, un rapport constant spécifique au sol a été trouvé pour un sable limoneux. Dans les essais contrôlés par la vitesse de déformation, on a comparé un sable à faible teneur en fines non plastiques et un sable en ayant une teneur significative. Les essais à vitesse de déformation constante ne montraient pratiquement aucune dépendance vis-à-vis du taux de déformation pour le sable avec peu de fines et une dépendance de vitesse de déformation bien visible pour le sable très limoneux. Les essais avec une évolution progressive de la vitesse de déformation ont montré un comportement non-isotache pour le sable avec peu de fines et un comportement d'isotache pour l'autre. Les essais de relaxation de contrainte ont montré un comportement isochrone. L'analyse des trois effets visqueux dans les sables montre que tels effets ne peuvent pas être entièrement décrits par le biais des mathématiques dans le cadre du concept d'isotache. Un nouveau modèle de compression pour le comportement au fluage des sables est présenté. [Traduit par la Rédaction]

Mots-clés : sable, viscosité, fluage, dépendance vis-à-vis le taux, relaxation de contrainte.

\section{Introduction}

The mechanical behaviour of soil is time dependent. Time dependency is usually referred to as creep - describing the time-dependent development of strains under constant effective stress - and the dependency of the stress-strain relationship on the strain rate. The change of stress with time under constant strain - so called stress relaxation - is a special case of ratedependency at zero strain rate. Another important phenomenon of time dependency of soils is ageing. It describes the change of mechanical and hydraulic properties such as compressibility, shear strength, and hydraulic conductivity of the soil over time under constant effective stress. According to published research results, ageing is linked to the viscous properties of the soil (Mitchell and Solymar 1984; Schmertmann 1991; Jardine et al. 1999; Bowman and Soga 2003; Suarez 2012). However, ageing is not the focus of this study.
The viscous behaviour of fine-grained soils is a thermally activated process, which can be described successfully with the so called "rate process theory" originally developed for metals by Glasstone et al. (1941). Experimental findings of the viscous behaviour of fine-grained soils can be described using the creep law by Norton (1929) and the isotache concept by Šuklje (1957). Creep, strain rate dependency and stress relaxation of fine-grained soils can be described rather satisfactory by one soil-specific parameter, for example the viscosity index $I_{\mathrm{v}}$ (Leinenkugel 1976; Gudehus and Leinenkugel 1978; Klobe 1992; Krieg 2000) and the ratio $C_{\alpha} / C_{\mathrm{c}}$, where $C_{\alpha}$ is the creep coefficient and $C_{\mathrm{c}}$ is the compression index, with $I_{\mathrm{v}}=C_{\alpha} / C_{\mathrm{c}}$ (Mesri and Castro 1987).

The viscous behaviour of granular soils depends on the applied effective stress, the density, the stiffness, and strength of the grains hence the mineralogy, the grain shape, and the degree of saturation. It is directly related to the amount of particle crushing (Karimpour and Lade 2010). The load transfer in granular soils

Received 27 September 2017. Accepted 13 April 2018.

F. Levin, S. Vogt, and R. Cudmani. Department of Civil, Geo and Environmental Engineering, Technical University of Munich, Baumbachstraße 7, 81245 Munich, Germany.

Corresponding author: Friedrich Levin (email: f.levin@tum.de).

Copyright remains with the author(s) or their institution(s). Permission for reuse (free in most cases) can be obtained from RightsLink. 
happens through force chains that form an inhomogeneous network in the grain assembly (Eber 2006). Weakly loaded grain clusters between the force chains support them laterally. The forces transferred by heavily loaded force chains can reach values of up to six times the mean sample loading (Radjai et al. 1996). The micromechanical configuration of force chains can shift under external influences - for example, vibrations or change in the stress state - or due to time-dependent effects such as degradation of the grain surface or grain breakage leading to a change of structure in the granular soil and hence macroscopic deformation (Bowman and Soga 2003; Michalowski and Nadukuru 2012). According to Jardine et al. (1999), creep in granular soil can be understood as the gradual stabilization of the process in which force chains can fail because of yielding or buckling (loss of stability). The failure of the force chains starts with particle rearrangements in weakly loaded clusters. Because of the comparably very low loading, the grain contacts can only transmit very little shear forces at the grain contacts. The rearrangement leads to a withdrawal of the lateral support from the heavily loaded force chains, which subsequently buckle. This process slows down with time as normal contact forces transmit more of the mean stress in the sample and the network of heavily loaded force chains becomes self-supporting (Bowman and Soga 2003; Wang et al. 2014).

All micromechanical changes in the granular skeleton leading to creep result from particle rearrangements due to grain translation, rotation or degradation. The mechanism depends on the stress level, void ratio, and initial geometrical configuration of the grains, which may be referred to as the soil structure (Mejia and Vaid 1988; Colliat-Dangus et al. 1988; Mesri and Vardhanabhuti 2009). The micromechanical processes of time-dependent degradation at the grain contacts and different forms of delayed grain breakage are considered to be the key mechanisms behind creep that can be measured macroscopically in granular soils (Leung et al. 1996; McDowell and Khan 2003; Kwok and Bolton 2013).

The necessity to account for time- and rate-dependent behaviour of granular soils in geotechnical design has only become clear in recent years. Mostly, for the considered scales of geometry and time in certain engineering problems, time effects are insignificant and can be neglected. However, there are geotechnical challenges in which time effects cannot be disregarded. Dumps of granular soils from mining activities show significant long lasting delayed deformations resulting from even small creep strains because of their large thickness. The dump surfaces of open cast mines near Cologne (Germany), which consist of unsaturated sands with thicknesses of more than $300 \mathrm{~m}$, settle several decimetres to metres over decades (Lange 1986; Kothen and Knufinke 1990; Vogt et al. 2013). Similar observations were made in mine tailings around the world (Charles-Cruz et al. 2008). The long-term monitoring of a quayside in the Port of Botany (Sydney) founded on a $20 \mathrm{~m}$ thick dumped and vibrocompacted sand layer - showed continuous deformations over 40 years (Cudmani et al. 2011).

Regarding strain rate effects, granular soils exhibit very abundant and various effects. This was investigated by Tatsuoka et al. (2002, 2008), Di Benedetto et al. (2002), Duttine and Tatsuoka (2009), Enomoto et al. (2009) and Peng et al. (2010). Different stress responses resulting from a sudden change of the strain rate are classified as

1. Isotache behaviour as it is well known from fine-grained soils;

2. Combined behaviour of isotache and nonisotache type where the stress change from a sudden strain rate change decreases with ongoing straining;

3. Temporary effect of strain rate and acceleration (TESRA) behaviour, in which the stress-strain curve after a sudden change in strain rate gradually approaches a quasi-unique rate-independent stress-strain curve; and
Table 1. Influence of granulometric properties on rate-dependent behaviour of granular soils according to Enomoto et al. (2009); as modified from Tatsuoka (2007).

\begin{tabular}{ll}
\hline Influencing factor & $\begin{array}{l}\text { Rate-dependent behaviour }: \\
\text { Isotache } \rightarrow \text { combined } \rightarrow \text { TESRA } \rightarrow \text { P\&N }\end{array}$ \\
\hline $\begin{array}{l}\text { Particle shape } \\
\text { (stiff particles) }\end{array}$ & More angular $\rightarrow$ more round \\
$\begin{array}{l}\text { Grading } \\
\text { Particle size }\end{array}$ & $\begin{array}{l}\text { Well graded } \rightarrow \text { poorly graded } \\
\text { Particle crushability } \\
\text { (mineral hardness) }\end{array}$ \\
$\begin{array}{l}\text { Interparticle bonding } \\
\text { More crushable } \rightarrow \text { less crushable }\end{array}$ & Stronger $\rightarrow$ weaker $\rightarrow$ zero \\
\hline
\end{tabular}

4. Positive-negative $(\mathrm{P} \& \mathrm{~N})$ behaviour where the stress-strain curve drops with ongoing straining below an unique rateindependent stress-strain curve (Tatsuoka et al. 2008).

Mainly granular and mineralogical properties of the material govern the rate-dependent behaviour. Qualitative relationships between the observed viscous behaviour and granulometric properties were presented by Enomoto et al. (2009) (see Table 1). The effect of different, but throughout the monotonous loading of a sample constant, strain rates on the stress-strain response of granular soil was reported to be very small. An influence of the rate of loading on the creep strains and the stress relaxation was found by Karimpour and Lade (2010), who performed triaxial tests on Virginia Beach sand. Creep strains increased with increasing previous loading rate and the relaxation rate was also higher at larger loading rate, but quickly converged to a rate independent of the loading rate previously applied to the sample. Karimpour and Lade (2010) relate the creep and relaxation behaviour to the different times given to the grain assembly to adjust to the amount of grain breakage and grain contact degradation, respectively, that is reduced during fast loading prior to a phase of creep or stress relaxation.

Experimental findings show that the relaxation behaviour of granular and fine-grained soils are qualitatively different. The relaxation effect in coarse-grained soils is much larger than the viscous effects rising from creep or a stepwise change in the strain rate (Pham Van Bang et al. 2007; Lade 2009; Lade et al. 2009; Lade and Karimpour 2014). This cannot be described in the framework of the isotache concept. Pham Van Bang et al. (2007) showed that the relaxation behaviour is also highly stress path dependent. However, the stress-relaxation tests by Pham Van Bang et al. (2007), Lade (2009), and Lade et al. (2009) were not true relaxation tests in terms of constant void ratio at constant principal strain. They were performed under cylindrical stress conditions in a drained triaxial setup and the zero strain rate condition was only applied for the axial strain component $\left(\dot{\varepsilon}_{1}=0, \dot{\varepsilon}_{3} \neq 0, \dot{\sigma}_{1}^{\prime} \neq 0\right.$, $\dot{\sigma}_{3}^{\prime}=0$, where $\dot{\varepsilon}_{1}$ is the major principal strain rate, $\dot{\varepsilon}_{3}$ is the minor principal strain rate, $\dot{\sigma}_{1}^{\prime}$ is the major principal effective stress rate, and $\dot{\sigma}_{3}^{\prime}$ is the minor principal effective stress rate). A comparison of drained to undrained $\left(\dot{\varepsilon}_{1}=0, \dot{\varepsilon}_{3}=0, \dot{\sigma}_{1}^{\prime} \neq 0, \dot{\sigma}_{3}^{\prime} \neq 0\right)$ triaxial relaxation tests by Lade and Karimpour (2014) showed very similar relaxation of the deviator stress $q$. The drained tests showed contractive behaviour while the undrained tests were in some cases dilative leading to negative pore water pressures. This influences the relaxation of the effective mean stress $p^{\prime}$ and may cause different relaxation behaviour of $p^{\prime}$ in drained and undrained tests.

This study focusses on the three main macroscopic expressions of viscosity of granular soils, i.e., creep, strain rate dependency, and stress relaxation and gives a concise set of experimental results on all three phenomena. The compressive behaviour was evaluated for different soils, relative densities, stress levels, strain rates, and sudden changes in the strain rates. A focus lies on the comparison of pure sand to sand with high fine contents. To per- 
Table 2. Classification characteristics of investigated materials.

\begin{tabular}{llllllll}
\hline Origin & $\begin{array}{l}\text { Sample } \\
\text { name }\end{array}$ & $C_{\mathrm{u}}$ & $\begin{array}{l}\text { Content } \\
<0.063 \mathrm{~mm}(\%)\end{array}$ & $\begin{array}{l}d_{50} \\
(\mathrm{~mm})\end{array}$ & $e_{\min }$ & $e_{\max }$ & $\begin{array}{l}\rho_{\mathrm{s}} \\
\left(\mathrm{g} / \mathrm{cm}^{3}\right)\end{array}$ \\
\hline Cologne & FS & 1.38 & 6.4 & 0.170 & 0.776 & 1.144 & 2.614 \\
& MS & 2.11 & 2.8 & 0.340 & 0.628 & 1.088 & 2.604 \\
& SU & 5.13 & 14.3 & 0.170 & 0.755 & $1.154^{*}$ & 2.630 \\
Munich & SU2 & 3.26 & 46.0 & 0.069 & 0.683 & $1.200^{*}$ & 2.728 \\
\hline
\end{tabular}

Note: $C_{\mathrm{u}}$, uniformity coefficient; $d_{50}$, grain diameter at $50 \%$ cumulative mass; $e_{\min }, e_{\max }$, minimum and maximum void ratios, respectively; $\rho_{\mathrm{s}}$, density of solid particles.

${ }^{*} \mathrm{SU}$ and SU2 were classified by $e_{\min }$ and $e_{\max }$ because the fines (by definition of DIN (2016) EN ISO 17892-4 content $<0.063 \mathrm{~mm}$ ) consisted predominantly of coarse nonplastic silt particles resulting in soil behaviour comparable to that of fine sands. Determination of Atterberg limits for SU and SU2 was not possible.

Fig. 1. Optical micrographs of (a) MS, (b) FS, (c) SU and (d) SU2). [Colour online.]

(a)

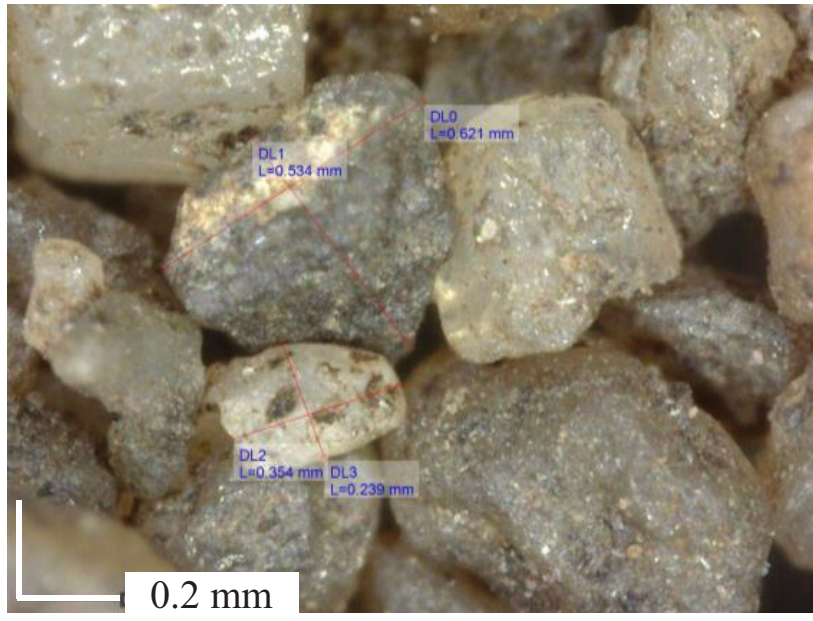

(c)

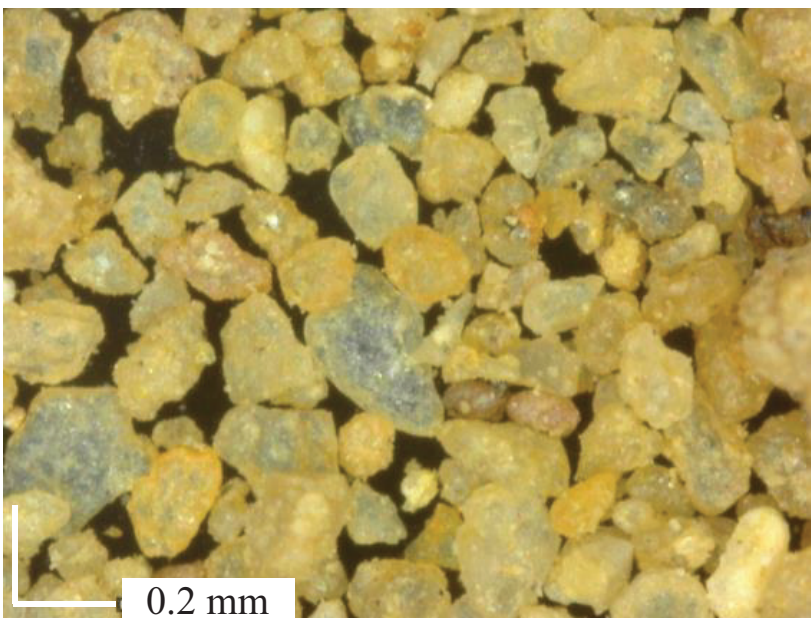

form true relaxation tests, the experimental setup of an oedometer is chosen in this study. Furthermore, the applicability of the isotache concept will be evaluated and a new approach to model the compressive creep behaviour of granular soils will be presented.

\section{Soils, specimen preparation, and testing procedures}

The soils used were three sands from the Rhenish lignite mining area near Cologne (Germany) with subangular to rounded particles and one sand from a quarry near Munich (Germany) with angular to subangular grains. The mineralogical components of the sands from Cologne were 93\% to $97 \%$ quartz and $3 \%$ to $7 \%$ orthoclase. The sand from Munich had $41 \%$ dolomite, 30\% calcite, $22 \%$ quartz, $3 \%$ albite, $2 \%$ kaolinite, and $1 \%$ orthoclase as well (b)

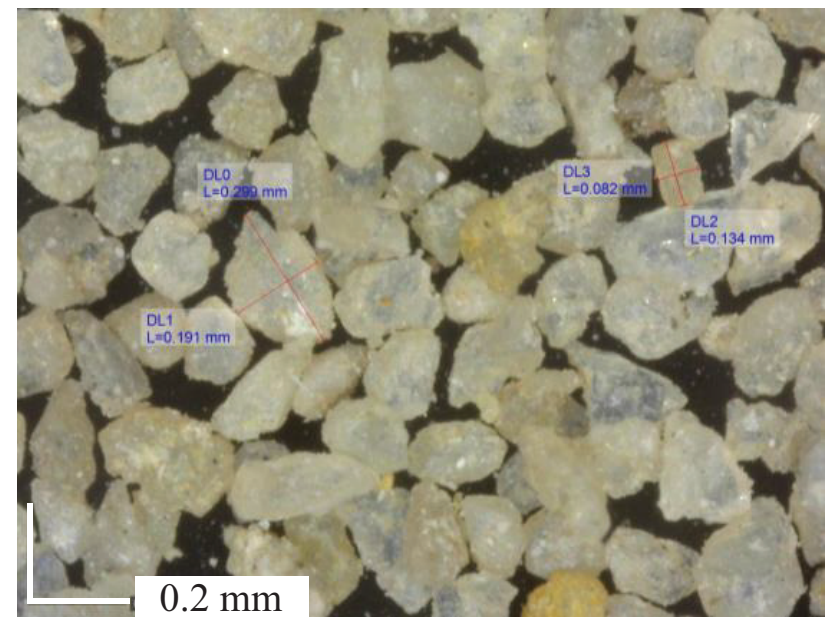

(d)

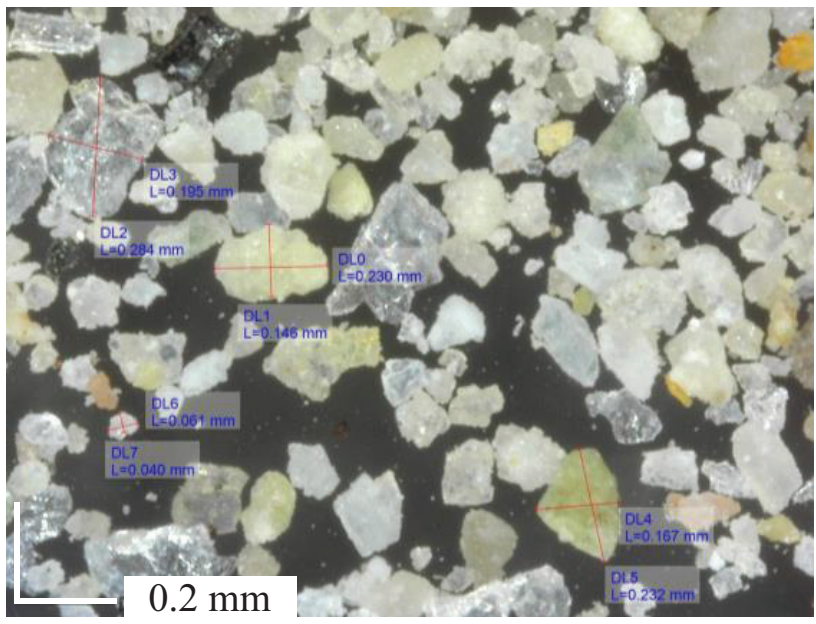

as $1 \%$ muscovite. The sands from Cologne were a fine sand (FS) with $6.4 \%$ content of fines, a medium sand with a content of fines of $2.8 \%$ (MS), and a silty sand with $14 \%$ silt content (SU). The sand from Munich was a silty sand with $46 \%$ silt content (SU2). Soils FS, MS, and SU2 were uniform and SU nonuniform and all samples were poorly graded. Table 2 summarizes the classification characteristics, Fig. 1 shows micrographs of the sands, and Fig. 2 presents the grain-size distributions.

The sample size in the oedometer devices was $100 \mathrm{~mm}$ in diameter and $20 \mathrm{~mm}$ in height. All specimens were air dried, prepared by funnel deposition, and carefully levelled with a steel ruler. With this preparation technique, minimum relative densities of approximately $D_{R}=0.3$ (loose) were achieved. For the preparation 
Fig. 2. Grain-size distributions of investigated soils: MS, FS, SU, and SU2.

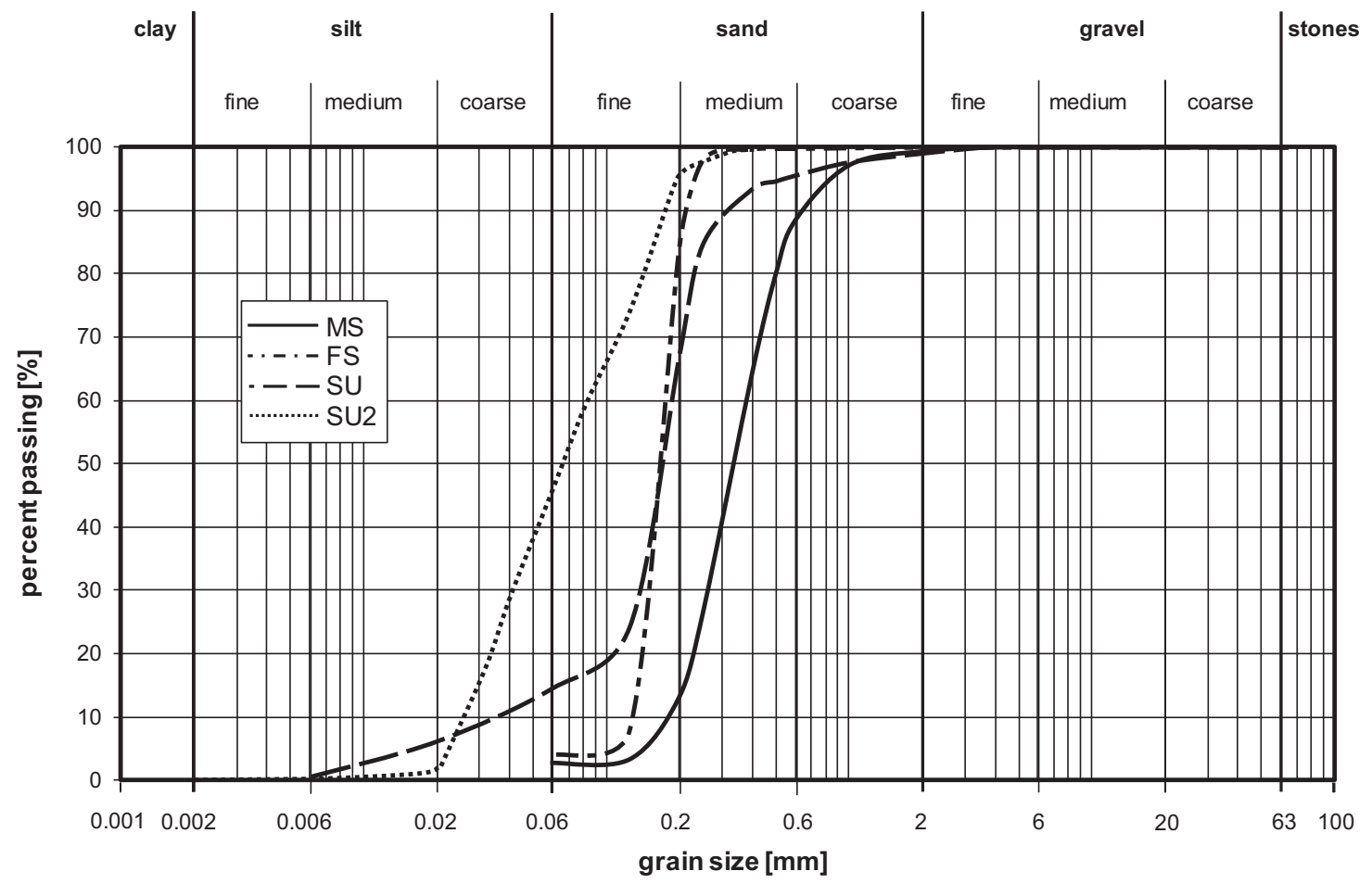

of dense samples, the specimens were compacted by lateral hammer blows to the side of the oedometer. The prepared maximum relative density was $D_{R}=1.0$ (very dense). For a precise determination of the initial relative density of the samples, the pre-mounted vertical displacement transducer was set to zero at an exact sample height of $20 \mathrm{~mm}$. The settlement resulting from the application of the loading plate could thereby be determined. All tests were performed under temperature-controlled conditions with a maximum temperature fluctuation during 1 day of $0.5{ }^{\circ} \mathrm{C}$ at a mean temperature of $23{ }^{\circ} \mathrm{C}$. Vertical deformation of the sample was measured with a resolution and accuracy of $1.0 \mu \mathrm{m}$. The loadcontrolled tests (LC) were conducted with weights acting on a lever arm system, ensuring a truly constant vertical load on the specimen during creep. The strain-controlled tests including the relaxation tests were performed in a computer-controlled electromechanical load frame. A possible machine influence on the stress-strain curve due to inertia upon strain rate change was evaluated by loading a system of plate springs and found to be negligible. In addition, a possible stress relaxation resulting from the load frame was checked and also found to be negligible.

\section{Experimental program}

A total of 29 load-controlled and 32 strain rate-controlled as well as five relaxation oedometer tests were performed, from which representative results are presented. All tests were carried out with air-dried samples. The LC were carried out by doubling the vertical stress on the sample every $24 \mathrm{~h}$ up to $2000 \mathrm{kPa}$. The strain rate-controlled tests were performed up to $1000 \mathrm{kPa}$ with some tests up to $2000 \mathrm{kPa}$. They were carried out with a constant rate of strain (CRS) and with sudden changes in the strain rate at certain stress levels (ChRS). Definition of engineering strain was used, relating the sample deformation to the initial sample dimensions. Relaxation tests were conducted with relaxation phases of $1 \mathrm{~h}$ at stress levels of 200,500, and $1000 \mathrm{kPa}$. A difficulty during the relaxation tests was to ensure zero vertical deformation of the sample because during relaxation the load frame and the vertical load cell expand due to the stress decrease. To counterbalance this expansion, the load frame was controlled by a closed loop real- time control with a threshold of $1.0 \mu \mathrm{m}$ in vertical deformation upon which the load frame reacted and compensated the deformation. This led in some tests to small stress jumps, but guaranteed the zero deformation criterion with a very high precision $(0.005 \%$ of the initial sample height).

\section{Evaluation methods}

A simple approach for evaluating the results from the experiments conducted is to treat the volumetric deformations due to stress changes, creep, and imposed strain rate separately. For the evaluation of the change in void ratio $\Delta e$ with vertical stress, the compression index $C_{\mathrm{c}}$ for loading and the swelling index $C_{\mathrm{s}}$ for unloading-reloading were used

$$
C_{\mathrm{c}}=\frac{\Delta e}{\Delta \log \sigma^{\prime}} \quad C_{\mathrm{s}}=\frac{\Delta e}{\Delta \log \sigma^{\prime}}
$$

where $\sigma^{\prime}$ is the vertical effective stress.

These indexes were evaluated as secant moduli $60 \mathrm{~s}$ after a sudden stress change $\Delta \log \left(\sigma^{\prime}\right)$ in the LC and continuously as a tangent modulus in the strain rate-controlled tests. Equation (1) approximates the void ratio over the logarithm of the stress with a straight line. This approximation was proposed for the description of the behaviour of fine-grained soils under oedometric conditions (Taylor 1948). In granular soils, the relationship between $\Delta e$ and $\log \left(\sigma^{\prime}\right)$ is nonlinear (Bauer 1992). Linearity can only be assumed for small stress increments. Other approaches were proposed by (Terzaghi 1925) (see eq. (2)) with a corrective stress $\Delta \sigma^{*}$, which accounts for the deviation of the semi-logarithmic compression curve from a straight line and Bauer (1996) (see eq. (3)), who considered an exponential compression law

$$
\begin{aligned}
& C_{\mathrm{c}}^{*}=\frac{\Delta e}{\Delta \log \left(\sigma^{\prime}+\Delta \sigma^{*}\right)} \\
& \frac{e}{e_{0}}=1 / \exp \left[\left(3 p^{\prime} / h_{\mathrm{s}}\right)^{n}\right]
\end{aligned}
$$


Fig. 3. (a) Idealized time-dependent (viscous) stress-strain behaviour of fine-grained soils during oedometric compression, (b) relationship between creep, rate dependency, and relaxation according to Krieg (2000). $\kappa$, swelling coefficient; $\lambda$, virgin compression coefficient.

(a)

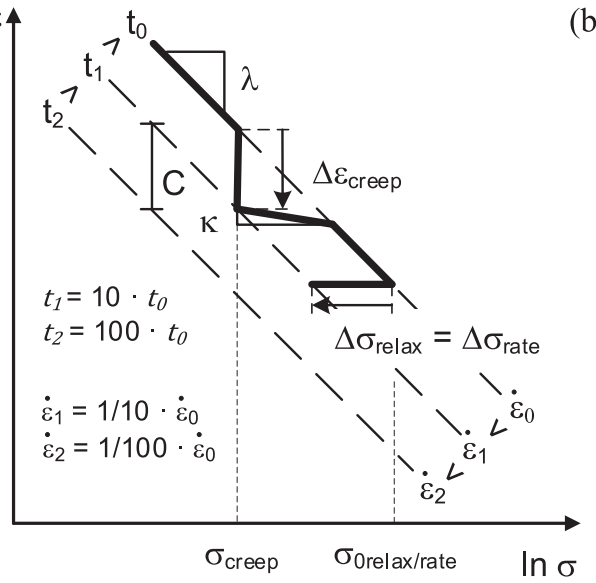

(b)

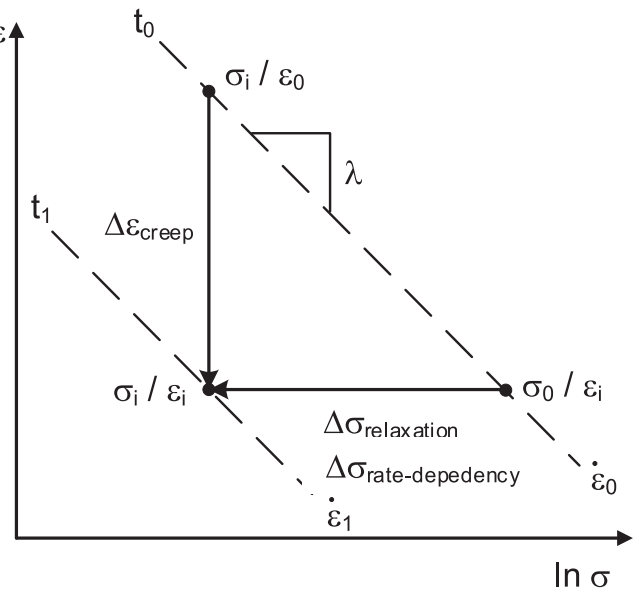

Fig. 4. (a) Semi-logarithmic virgin compression and unloading curves of medium dense and very dense samples of FS, MS, SU, and SU2, (b) $C_{\mathrm{c}}$ and $C_{\mathrm{s}}$ evaluation of all three soils with respect to vertical effective stress.

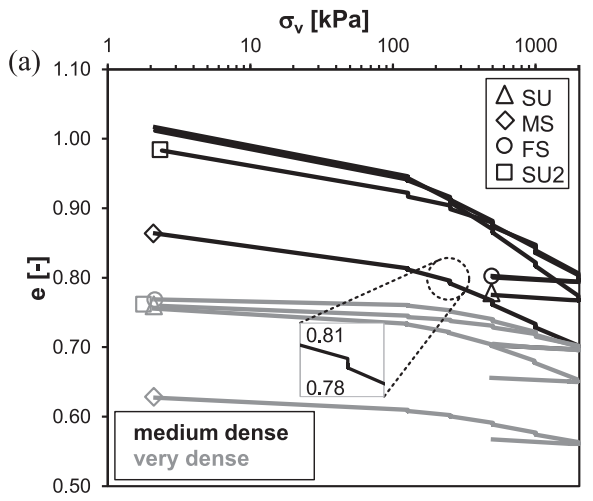

where $e_{0}$ is the initial void ratio at $p^{\prime}=0$ and $p^{\prime}$ is the effective mean stress. The so-called granular stiffness $h_{\mathrm{s}}$ and the exponent $n$ are soil-specific parameters. Despite these more suitable approaches, the stress dependent compression was analysed using eq. (1) for the sake of comparison between a granular soil and a fine-grained soil behaviour.

Creep was evaluated using the creep coefficient $C_{\alpha}$, which describes the change in void ratio on a logarithmic time scale

$$
\text { (4) } \quad C_{\alpha}=\frac{\Delta e}{\Delta \log t}
$$

$C_{\alpha}$ was evaluated from the linear slope of the $\log (t)-e$ curve. Furthermore, creep and stress dependent compression were evaluated using the ratio $C_{\alpha} / C_{\mathrm{c}}$ according to Mesri and Godlewski (1977) and Mesri and Castro (1987). They postulated this ratio to be independent from time and stress for fine-grained soils as well as for granular soils (Mesri et al. 1990).

ChRS tests were evaluated using the viscosity index $I_{\mathrm{v}}$ by Gudehus and Leinenkugel (1978), which is a correlation coefficient between the change in stress upon a change in the strain rate, relaxation time, and creep time. Equation (5) describes the relationship between creep, compression, relaxation, and rate dependency using $I_{\mathrm{v}}$

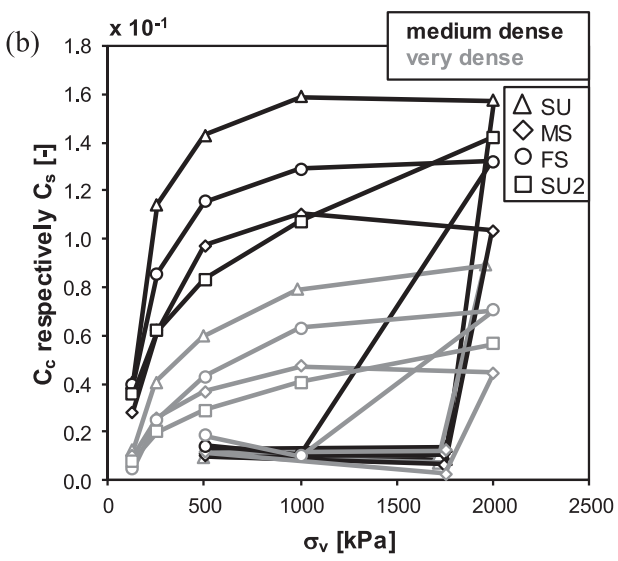

(5) $\underbrace{\frac{\left(\frac{\sigma_{0}^{\prime}}{\sigma_{i}^{\prime}}\right)}{\text { compression }} \rightarrow}_{\text {relaxation }}=\frac{\text { creep rate } \rightarrow}{\left(\frac{\dot{\varepsilon}_{0}}{\dot{\varepsilon}_{i}}\right)^{I_{\mathrm{v}}}}=\frac{\left.\frac{t_{i}}{t_{0}}\right)^{I_{\mathrm{v}}}=\left(\frac{t+t_{0}}{t_{0}}\right)^{I_{\mathrm{V}}}}{\text { relaxation time }}$

where $\sigma_{0}^{\prime}$ and $\sigma_{i}^{\prime}$ are the stresses before and after the strain rate change, at the beginning and the end of relaxation or before and after loading, respectively. $\dot{\varepsilon}_{0}$ and $\dot{\varepsilon}_{i}$ are the strain rates before and after a jump in the strain rate or the creep rate at time $t_{0}$ and $t_{i}$, respectively, where $t_{0}$ and $t_{i}$ are the start and end time of the considered creep or relaxation time interval, respectively, with $t_{0}<t_{i}$ (see Fig. 3). Equation (5) can be separated into the three appearances of soil viscosity

$$
\begin{aligned}
& \text { Relaxation }\left(\frac{\sigma_{0}^{\prime}}{\sigma_{i}^{\prime}}\right)=\left(\frac{t_{i}}{t_{0}}\right)^{I_{\mathrm{v}}} \\
& \dot{\varepsilon} \text { jump }\left(\frac{\sigma_{0}^{\prime}}{\sigma_{i}^{\prime}}\right)=\left(\frac{\dot{\varepsilon}_{0}}{\dot{\varepsilon}_{i}}\right)^{I_{\mathrm{V}}}
\end{aligned}
$$

and

$$
\text { Creep } \varepsilon_{i}-\varepsilon_{0}=C\left[\ln \left(\frac{t_{i}}{t_{0}}\right)\right]=C\left[\ln \left(\frac{\dot{\varepsilon}_{0}}{\dot{\varepsilon}_{i}}\right)\right] \quad \text { with } \frac{t_{i}}{t_{0}}=\frac{\dot{\varepsilon}_{0}}{\dot{\varepsilon}_{i}}
$$


Fig. 5. Void ratio $e$ over initial void ratio immediately after loading $e_{0}$ with logarithm of time of medium dense and very dense samples of (a) MS, (b) FS, (c) SU, and (d) SU2. (e) Creep coefficient $C_{\alpha}$ of all soils in virgin loading and unloading with respect to vertical effective stress.
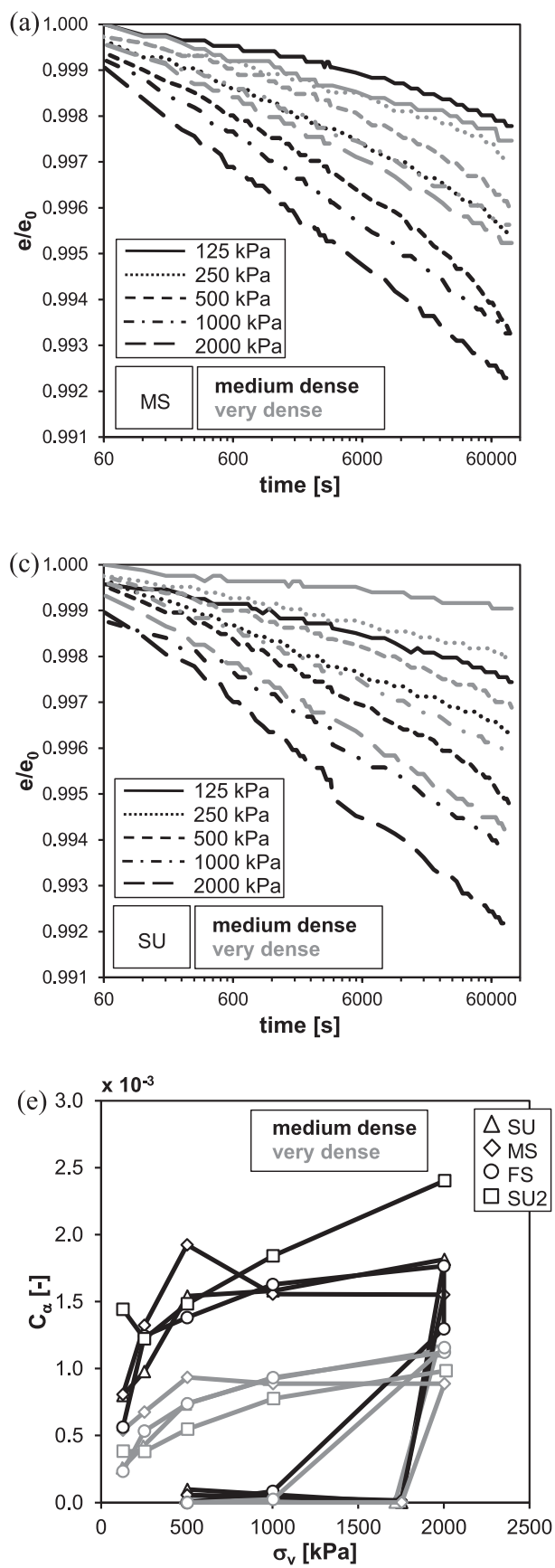

From this it follows that

$$
\begin{array}{r}
\lambda\left[\ln \left(\frac{\sigma_{0}^{\prime}}{\sigma_{i}^{\prime}}\right)\right]=C\left[\ln \left(\frac{t_{i}}{t_{0}}\right)\right]=C\left[\ln \left(\frac{\dot{\varepsilon}_{0}}{\dot{\varepsilon}_{i}}\right)\right] \\
\text { or } \frac{\sigma_{0}^{\prime}}{\sigma_{i}^{\prime}}=\left(\frac{t_{i}}{t_{0}}\right)^{C / \lambda}=\left(\frac{\dot{\varepsilon}_{0}}{\dot{\varepsilon}_{i}}\right)^{C / \lambda}
\end{array}
$$

Considering that the viscosity index $I_{\mathrm{v}}$ is equal to the ratio of $C_{\alpha} / C_{\mathrm{c}}$ and to $C / \lambda$ for fine-grained soils, where $C$ is the creep coefficient reference to the strain rather than the void ratio and $\lambda$ is the virgin compression coefficient (Klobe 1992; Krieg 2000), eq. (9) can be rewritten to
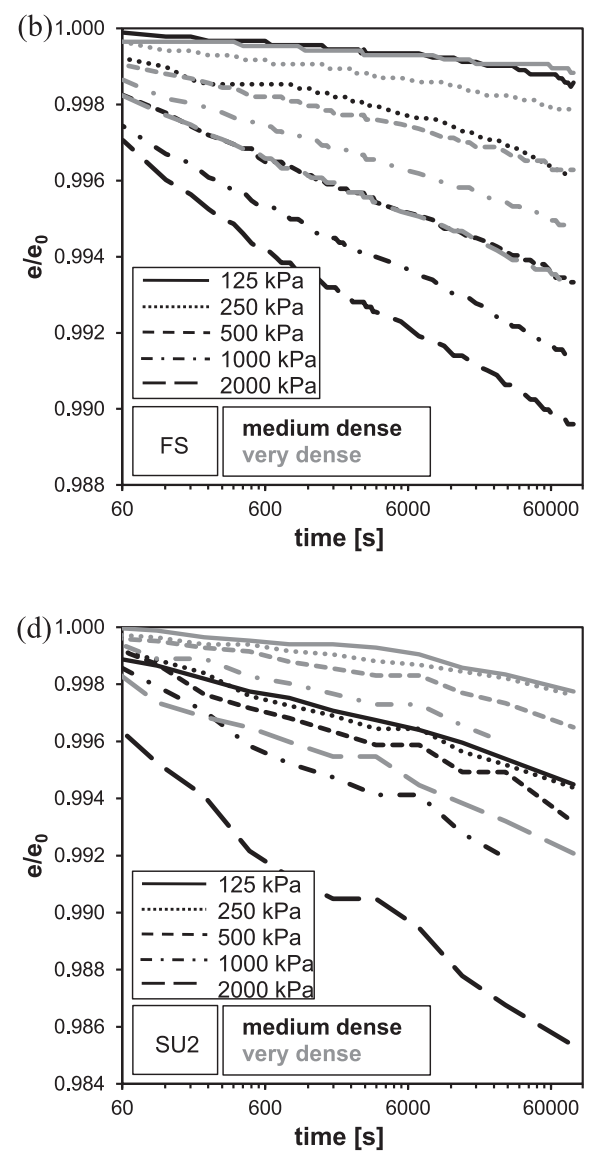

(10) $\quad \frac{\sigma_{0}^{\prime}}{\sigma_{i}^{\prime}}=\left(\frac{t_{i}}{t_{0}}\right)^{I_{\mathrm{v}}}=\left(\frac{\dot{\varepsilon}_{0}}{\dot{\varepsilon}_{i}}\right)^{I_{\mathrm{v}}}$

One aim of this study is to investigate whether relationship at eq. (5) holds and the assumption of a constant ratio $C_{\alpha} / C_{\mathrm{c}}$ is applicable for granular soils.

\section{Experimental results}

To evaluate the possible influence of particle breakage the grain-size distributions of the tested soils before (see Fig. 2) and after the oedometric loading were determined. To obtain a satisfying amount of material for performing robust sieving analysis, 
Fig. 6. $C_{\alpha} / C_{c}$ evaluation for (a) MS, (b) FS, (c) SU, and (d) SU2.
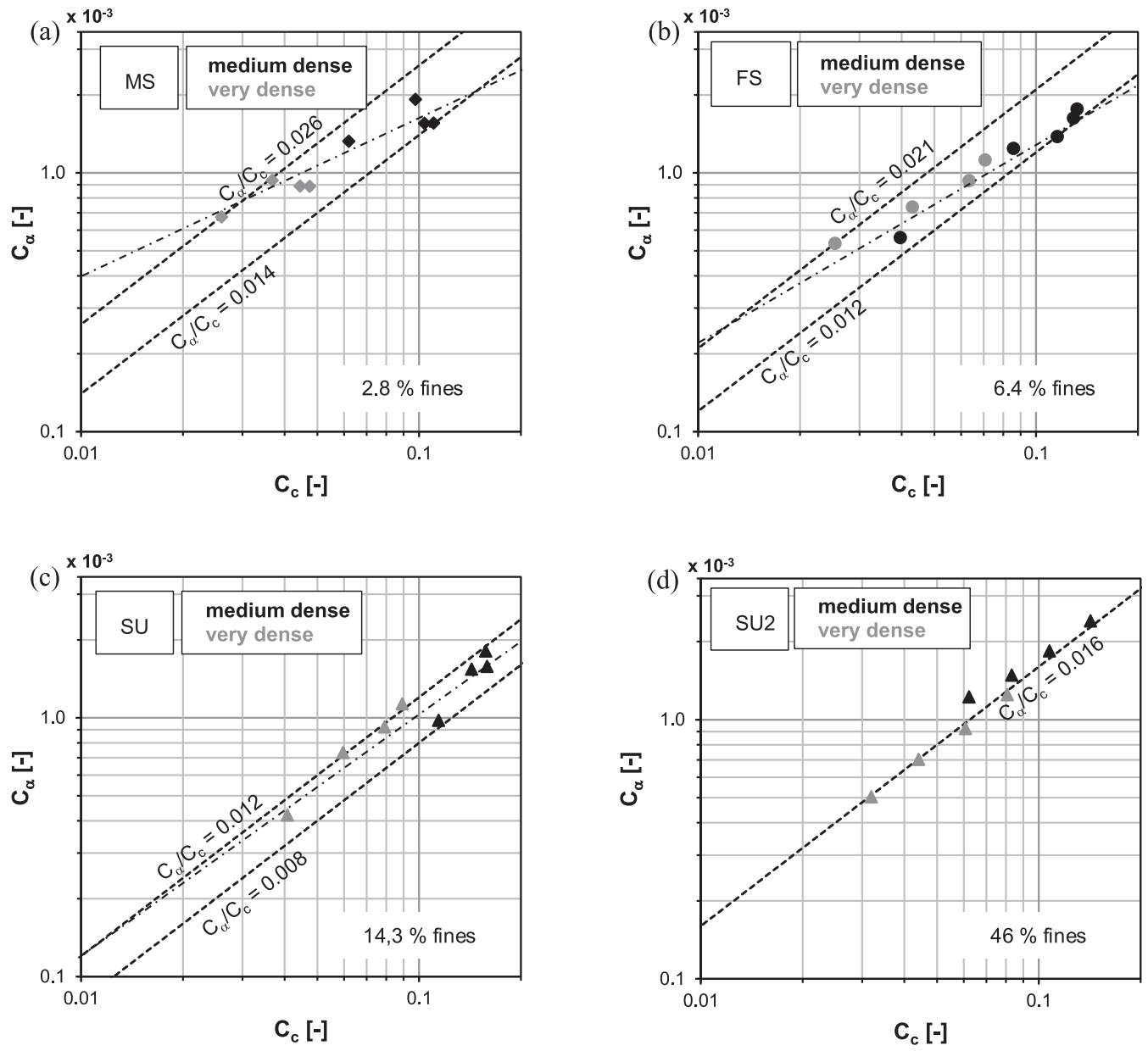

Fig. 7. Constant rate of strain (CRS) tests on (a) MS and (b) SU2 by applying two strain rates with ratio of 1000.

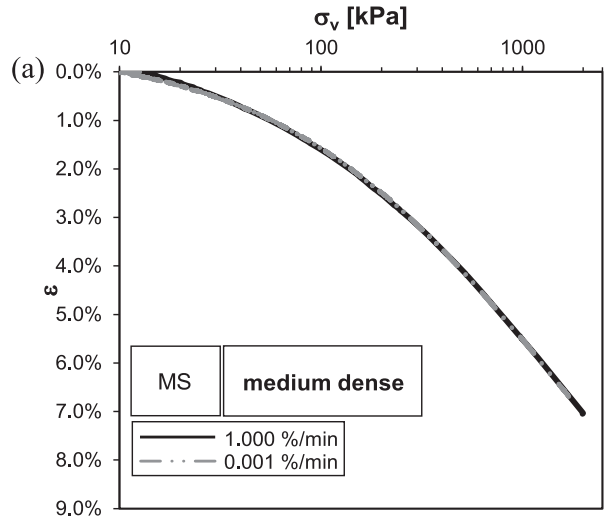

the soil was collected and put together from several oedometer samples of a testing series each. No changes in the grain-size distributions could be detected. This indicates that the deformation mechanism up to vertical stresses of $2000 \mathrm{kPa}$ in the oedometric tests with the given sands is dominated by translation and rotation of the grains and that particle damage is limited to abrasion or breakage at the grain contacts, which is not detectable by sieving analysis.

\section{Load-controlled tests}

Load-controlled tests were performed with load steps of 125 , $250,500,1000$, and $2000 \mathrm{kPa}$. At each stress level, the soil was left

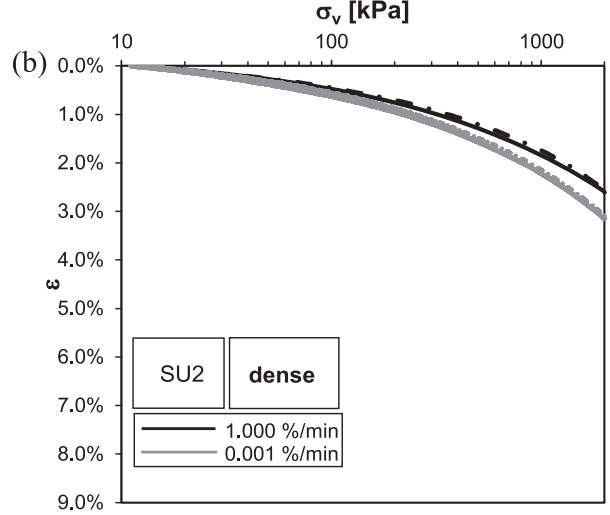

to creep for $24 \mathrm{~h}$. In some tests the samples were unloaded after the creep phase at the maximum applied stress of $2000 \mathrm{kPa}$. Figure $4 a$ shows the semi-logarithmic plot of the development of the void ratio $e$ with the applied vertical stress $\sigma_{\mathrm{v}}$ during virgin loading, creep and unloading for the four sands FS, MS, SU, and SU2. The creep stages are visible as vertical lines at each load stage (see magnified section in Fig. 4a). For determination of $C_{\mathrm{c}}$ and $C_{\mathrm{s}}$, the void ratio was evaluated $60 \mathrm{~s}$ after each load change. Figure $4 \mathrm{~b}$ depicts the obtained values of $C_{\mathrm{c}}$ and $C_{\mathrm{s}}$ according to eq. (1) with the void ratios $e$ as given by Fig. $4 a$. It is clearly visible from Figs. $4 a$ and $4 b$ that $C_{\mathrm{c}}$ increases with increasing vertical stress $\sigma_{\mathrm{v}}$. And the 
Fig. 8. Strain rate-controlled tests including sudden changes in strain rate of MS with (a) 200 -fold and (b) 10 -fold change in strain rate.
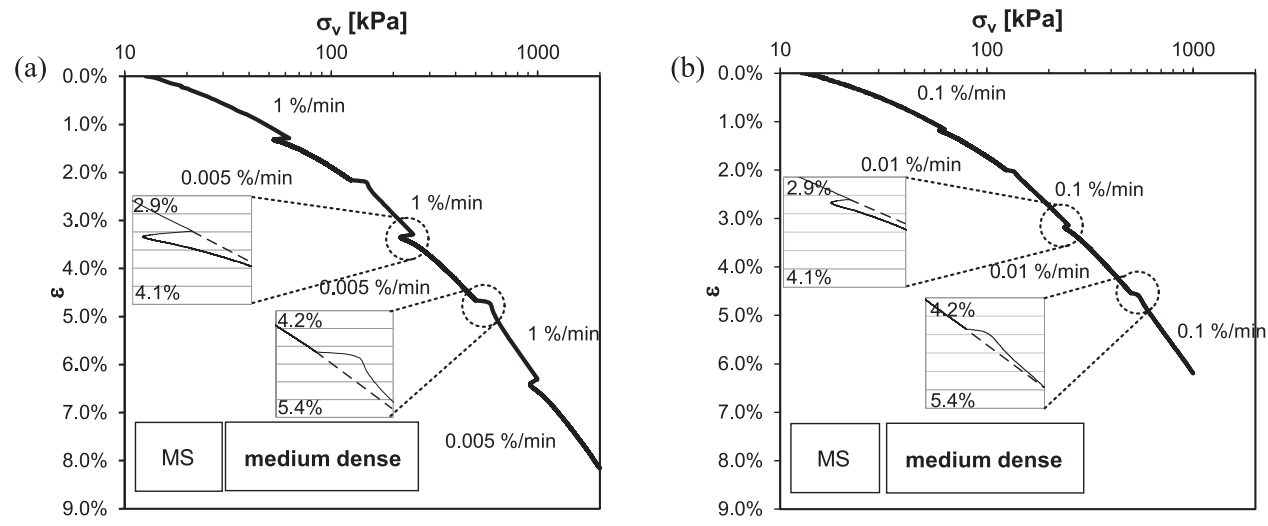

Fig. 9. Strain rate-controlled tests including sudden changes in strain rate of SU2 with (a) 200-fold and (b) 100-fold change in strain rate.
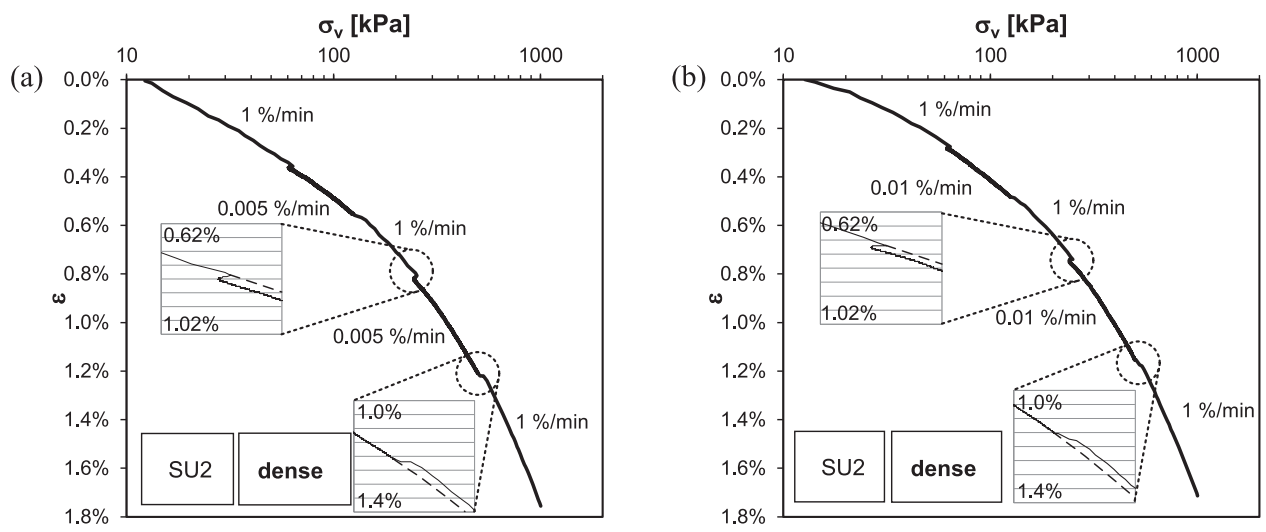

variation $\Delta C_{\mathrm{c}} / \Delta \sigma_{\mathrm{v}}$ decreases considerably with the vertical stress. The values are also dependent on the initial relative densities of the samples and on the granulometric properties of the soils. As expected, the compression index $C_{\mathrm{c}}$ is generally lower with decreasing fine content of the soils with the exception of SU2 where the grain shape and mineralogy are very different compared to the other sands. Upon unloading to a minimum vertical stress of $500 \mathrm{kPa}$, the swelling indexes of all three soils have similar values.

Figures $5 a, 5 b, 5 c$, and $5 d$ show the void ratio $e$ over the initial void ratio immediately after loading $e_{0}$ on a logarithmic time scale. The compression curves follow in general a linear trend with respect to the logarithm of time. Therefore, an evaluation of the creep strains using eq. (4) in the considered time interval seems reasonable. Figure $5 e$ depicts the evaluation of the creep coefficient $C_{\alpha}$ in dependence of the applied vertical stress. Just like in Fig. $4 b$ for the compression index $C_{\mathrm{c}}$, the creep coefficient $C_{\alpha}$ increases with increasing vertical stress and the intensity of creep depends on the initial relative density. Similar observations regarding the development of creep strains with increasing mean stress were made by Mejia and Vaid (1988), Lade and Liu (1998), Kuwano and Jardine (2002), and Lv et al. (2017). For the tested soils, the grain-size distributions do not have a significant influence on the creep strains, as all soils show very similar creep coefficient values. Creep strains after unloading are negligible.

Figure 6 presents the evaluation of the ratio $C_{\alpha} / C_{\mathrm{c}}$ from the LC. Depicted by dashed lines are ranges of $C_{\alpha} / C_{\mathrm{c}}$ for each soil as well as a dashed out line indicating the deviation of $C_{\alpha} / C_{\mathrm{c}}$ from a constant soil-specific value according to a best-fit correlation for the obtained test results. In the diagrams, the fine content $(<0.063 \mathrm{~mm})$ is given. With decreasing fine content, the deviation of $C_{\alpha} / C_{\mathrm{c}}$ from a constant soil-specific value increases. This is mainly because, in the tests, the increase of $C_{c}$ with the vertical stress is larger than the increase of $C_{\alpha}$. At a fine content of $14.3 \%$, the ratio $C_{\alpha} / C_{\mathrm{c}}$ ap-

proaches an almost constant value and, at a fine content of $46 \%$, the soil behaviour can be very well described with one constant ratio $C_{\alpha} / C_{c^{*}}$

\section{Constant rate of strain (CRS) tests}

Previous studies on granular soils by Tatsuoka et al. (2002), Di Benedetto et al. (2002), Lade (2009), Lade et al. (2009), Karimpour and Lade (2010), and Lade and Karimpour (2014) reported no rate dependency of the stress-strain relationship during CRS tests. Figure 7 shows the results of MS, with $2.8 \%$ and SU2 with $46 \%$ content of fines. The strain rate was varied by a factor of 1000. While the MS soil shows no significant dependency on the strain rate (Fig. 7a), the SU2 soil displays a well visible strain rate effect. As expected, the faster the strain rate, the stiffer the specimen's reaction. To rule out effects from sample preparation as apparent strain rate effect, each CRS test was performed twice at the same density.

\section{Strain rate-controlled tests including sudden changes in strain rate $(\mathrm{ChRS})$}

In the ChRS tests, the strain rate was varied stepwise (sudden) during loading at different stress levels. Figure 8 shows results of MS with medium density and Fig. $8 a$ showing 200 -fold strain rate change as well as Fig. $8 b 10$-fold strain rate change. Upon sudden strain rate change, there is a simultaneous stress change. After strain rate reduction, the stress decreases and, after strain rate increase, the stress increases. The change of the stress-strain curve seems to be reversible as the compression curve approaches, with ongoing straining, the curve it would have gone through without a sudden change in the strain rate. This kind of behaviour was also reported by Tatsuoka et al. (2002) and Di Benedetto et al. (2002) and called TESRA ("temporary effect of strain rate and acceleration"). From the two magnified sections in 
Fig. 10. Strain rate-controlled tests including sudden changes in strain rate (ChRS) together with CRS curve of (a) MS and (b) SU2 in dense state.

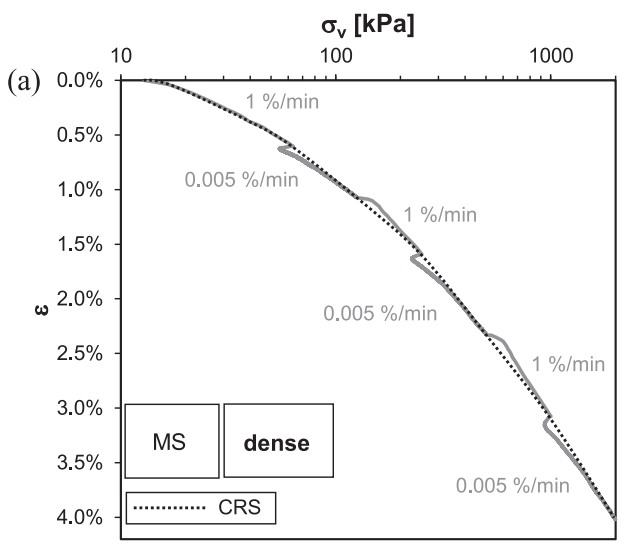

the diagrams, which have the same strain sectors, it can be seen that the intensity of the stress change depends on the difference in the strain rates. The larger the difference in the strain rates, the greater the change in the stress.

Figure 9 shows the results of SU2 in a dense state with Fig. $9 a$ showing 200 -fold and Fig. $9 b$ 100-fold strain rate change. The viscous reaction of the soil is much less pronounced than in MS. Opposite to the behaviour of the MS soil, a change in the stress-strain curve at a sudden change of strain rate seems to be permanent with continued straining. This corresponds to isotache behaviour (see also Fig. 10b). The intensity of the stress change depends on the difference in the strain rates as already identified for the MS sand (see the magnified sections in the diagrams).

For further investigation of the viscous behaviour of the two soils upon strain rate changes and to clarify whether TESRA or isotache behaviour is a valid characterization, Fig. 10 depicts two diagrams from Fig. 10a MS and Fig. 10b SU2 in a dense state, in which a ChRS test and the CRS line corresponding to the initial strain rate are presented. It can be seen from Fig. 10a that after a sudden strain rate change, the stress-strain curve of MS always approaches the CRS curve again, which indeed corresponds to TESRA behaviour. In the case of SU2 (Fig. 10b), it can be observed that the two lines remain parallel to each other after a sudden strain rate change, which indicates isotache behaviour.

Because tests with MS show TESRA behaviour, an objective evaluation of the viscosity index $I_{\mathrm{v}}$ is not possible as the stress change is only temporary. In the case of SU2, $I_{\mathrm{v}}$ was evaluated at each stress level where a sudden change in strain rate was applied using eq. (10) (see Fig. 11). The values show some scattering and they demonstrate the sensitivity of the $I_{v}$ value on the stress ratio as can be seen in Table 3. It therefore seems difficult to derive a representative value of $I_{\mathrm{v}}$ from ChRS tests with soils with no plastic fines.

\section{Repeatability of strain rate-controlled tests}

The repeatability of the strain rate-controlled experiments can be observed in Figs. 7-9. To additionally demonstrate sample preparation repeatability, Fig. 12 shows a CRS test and a ChRS test with samples with the same density and a loading sequence with the same strain rates. To check the repeatability, a loose density was chosen because it is most prone to deviations from sample preparation. Nevertheless, the stress-strain curves given by Fig. 12 are essentially the same.

\section{Relaxation tests}

Besides creep and rate dependency, the third viscous effect of soils is stress relaxation. True relaxation tests are defined by the boundary condition $\dot{\varepsilon}_{1}=\dot{\varepsilon}_{2}=\dot{\varepsilon}_{3}=0$, where $\dot{\varepsilon}_{2}$ is the medial principal strain rate. In oedometric testing, the strains are laterally constrained and only the vertical strain rate has to be con-

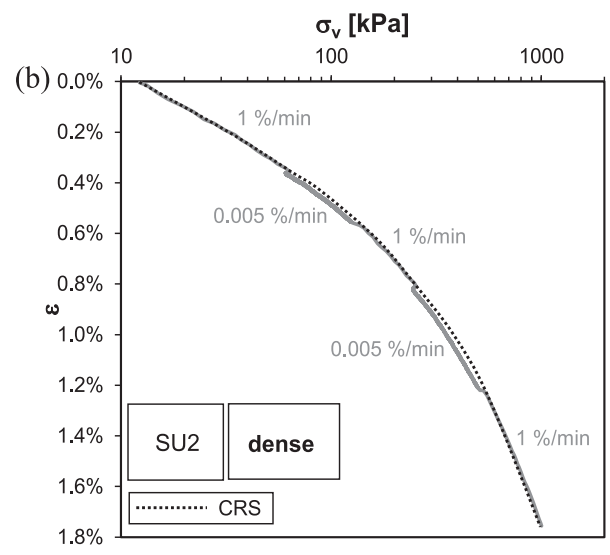

Fig. 11. Evaluation of ChRS tests of SU2 in dense state using viscosity index $\left(I_{\mathrm{v}}\right)$, with 100 - and 200 -fold strain rate change.

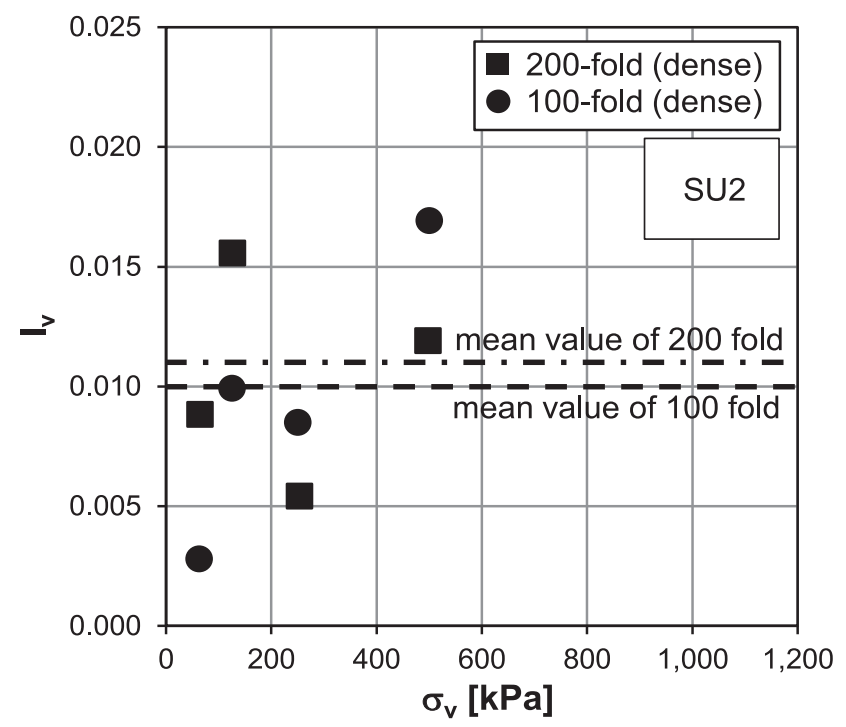

Table 3. Ratio and corresponding $I_{\mathrm{v}}$ for a 200 - and 100 -fold strain rate change of SU2 in dense state at different stress levels.

\begin{tabular}{llllll}
\hline & \multicolumn{2}{l}{200 fold } & & & \multicolumn{2}{l}{100 fold } & \\
\cline { 2 - 3 } Stress level $(\mathrm{kPa})$ & $\sigma_{\min } / \sigma_{\max }$ & $I_{\mathrm{v}}$ & & $\sigma_{\min } / \sigma_{\max }$ & $I_{\mathrm{v}}$ \\
\hline 62.5 & 0.98 & 0.009 & & 0.99 & 0.003 \\
125 & 0.95 & 0.016 & & 0.96 & 0.010 \\
250 & 0.96 & 0.005 & & 0.96 & 0.009 \\
500 & 0.94 & 0.012 & 0.93 & 0.017 \\
Mean & - & 0.011 & - & 0.010 \\
Standard deviation/mean & - & 0.34 & - & 0.5 \\
\hline
\end{tabular}

Note: $\sigma_{\min }$, effective vertical stress before strain rate jump; $\sigma_{\max }$, effective vertical stress after strain rate jump.

trolled. The tests were performed on samples of the MS soil with medium dense relative density. Relaxation phases were performed at 200,500, and $1000 \mathrm{kPa}$ for $1 \mathrm{~h}$ each. Figure 13 shows the results of a relaxation test on the MS sand loaded with a constant strain rate of $1.0 \% / \mathrm{min}$ between the relaxation phases. In Fig. 13a, the compression curve is depicted using a linear scale of the stress axis. The stress relaxation during a certain timespan depends on the stress level at which the relaxation is started. The stress relaxation in relation to the initial stress at which relaxation is started remains rather constant with a slight increase at larger stresses. 
Fig. 12. (a) Two CRS tests (strain rate of $1 \% /$ min each) for loose density and (b) two rate of strain tests including ChRS for loose density.
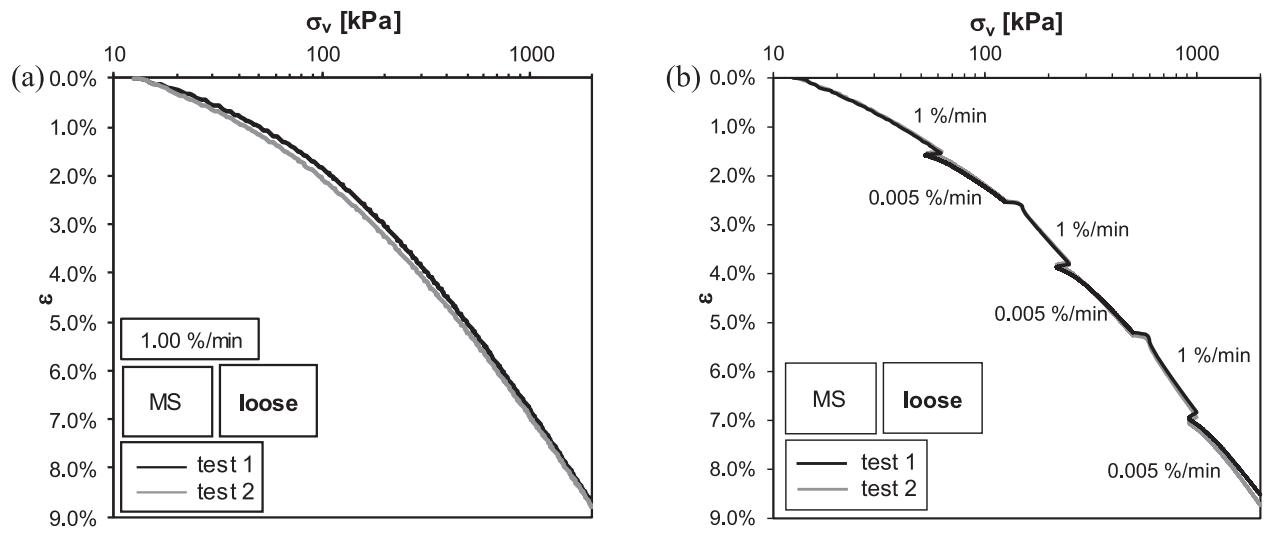

Fig. 13. Relaxation test on medium dense MS with relaxation phases of $1 \mathrm{~h}$ at 200,500 , and $1000 \mathrm{kPa}$ considering $(a)$ linear stress axis, (b) logarithmic stress axis, and (c) reduction of vertical stress with time in logarithmic scale.
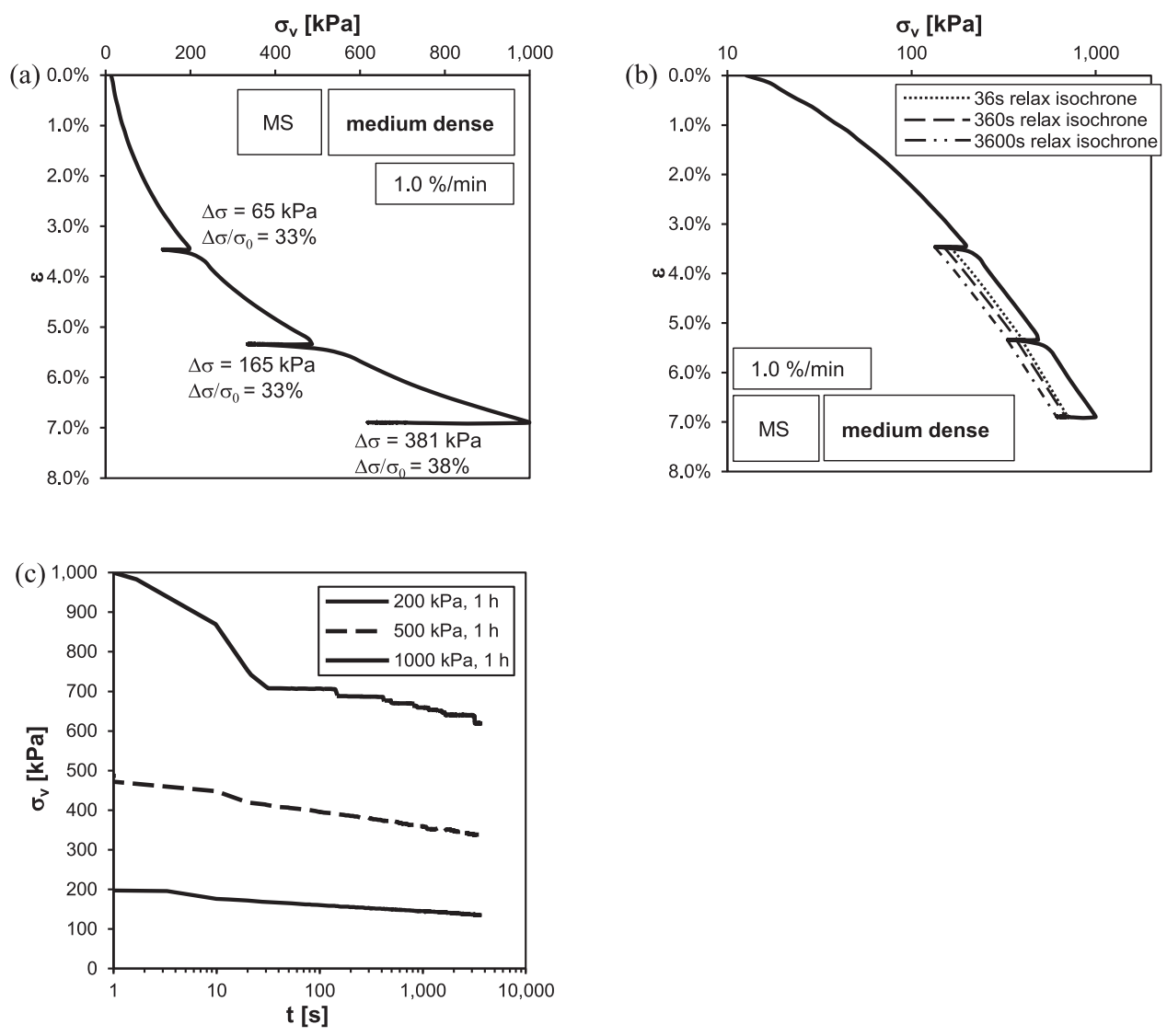

Plotting the compression curve using a logarithmic scaling of the stress axis (see Fig. 13b), the $36 \mathrm{~s}, 360 \mathrm{~s}$, and $1 \mathrm{~h}$ relaxation isochrones lie very parallel to each other and to the initial compression curve with only a slight deviation for the relaxation phase starting at a stress of $1000 \mathrm{kPa}$. This indicates a quasi-isochronous behaviour of the MS soil during relaxation. Figure $13 c$ presents the stress change over the logarithm of time at the three stress levels. The relaxation follows roughly a linear trend considering the logarithmic time scale with increasing gradient at larger stresses. The relaxation from $1000 \mathrm{kPa}$ deviates from the linear trend between 10 and $100 \mathrm{~s}$, which explains the deviating isochronic line at this stress level. The deviation was caused by the reaction of the load frame for compensation of the expansion of the load cell due to the stress decrease that is comparably large for a given threshold of

strain increment limited by an optic-digital displacement sensor owing to a resolution of $1 \mu \mathrm{m}$ because of the high soil stiffness.

\section{Comparing test results}

The time-dependent behaviour of most fine-grained soils can be well described by using the isotache concept (Šuklje 1957). Within this concept, the viscous behaviour of soils can be defined by one soil-specific parameter as given by the viscosity index $I_{v}$ (Leinenkugel 1976). Rate dependency and relaxation of those soils can be described using eqs. (6) and (7) and creep strains can be calculated using eq. (8), while the relationship between $C_{\alpha}$ and $I_{\mathrm{v}}$ follows eq. (10).

To investigate whether these relationships are valid for sands, the different kinds of viscous behaviour, which were previously 
Fig. 14. Comparison between effects of creep for $24 \mathrm{~h}$ versus relaxation over duration of $1 \mathrm{~h}$ on MS at medium dense relative density.

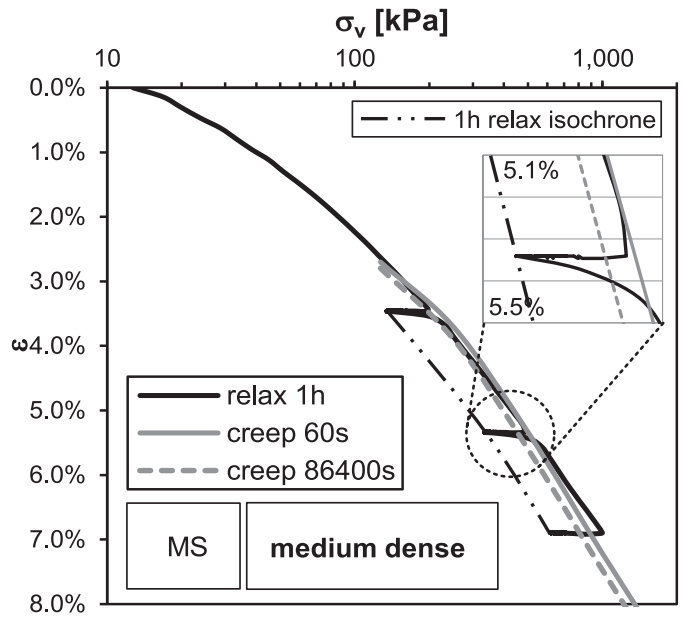

presented, are compared in the following. It was already shown that a constant stress and density independent value of the ratio $C_{\alpha} / C_{\mathrm{c}}$ is not valid for the MS sand (see Fig. 6) and the viscosity index $I_{\mathrm{v}}$ cannot be objectively evaluated from strain rate-controlled tests because the stress change is temporary (TESRA). However, the more fine-grained particles the soil contains, the better $C_{\alpha} / C_{\mathrm{c}}$ is applicable as a constant soil-specific value (see Fig. $6 d$ ). In case of the SU2 silty sand, objective values for $I_{\mathrm{V}}$ can be determined from strain rate-controlled tests, but show considerable scattering, which makes a comparison between $I_{\mathrm{v}}$ from ChRS test and $C_{\alpha} / C_{\mathrm{c}}$ from LC difficult.

To investigate the relationship between creep and relaxation in granular soils, the respective tests were plotted together in Fig. 14. A relaxation test and a creep test of MS at the same initial density are shown. The creep phases lasted for $24 \mathrm{~h}$ each and resulting isochronic lines are displayed together with a test including relaxation phases lasting for $1 \mathrm{~h}$ each. It can be clearly seen that the relaxation effect is far greater than the creep effect (see magnified section) even though the duration of the relaxation phases was much shorter than the duration of the creep phases. These results are in accordance with the findings by Lade (2009) and Lade et al. (2010).

An explanation for the difference is that stress relaxation is controlled by the comparably very high unloading stiffness of granular soils. Assuming the decomposition of the strain rate into an elastic and a viscous part according to a Maxwell element and together with the boundary condition of zero strain rate during relaxation, the following must hold for oedometric conditions:

$$
\dot{\varepsilon}=\dot{\varepsilon}_{\mathrm{v}}=\dot{\varepsilon}^{\mathrm{e}}+\dot{\varepsilon}^{\mathrm{vis}}=0
$$

Because the viscous strains will not be zero during relaxation, the granular skeleton must be unloaded for the elastic strains to compensate them and therefore follows

$$
-\dot{\varepsilon}^{\mathrm{e}}=\kappa^{0} \frac{d \sigma^{\prime}}{\sigma^{\prime}}=\dot{\varepsilon}^{\text {vis }}
$$

and

$$
d \sigma^{\prime}=-\dot{\varepsilon}^{\mathrm{e}}=\frac{\dot{\varepsilon}^{\mathrm{vis}}}{\kappa^{0}} \sigma^{\prime} \quad \text { or } \quad \kappa^{0}=\frac{\dot{\varepsilon}^{\mathrm{vis}}}{d \sigma^{\prime}} \sigma^{\prime}
$$

where $\dot{\varepsilon}_{\mathrm{v}}$ is the volumetric strain rate, $\dot{\varepsilon}^{\mathrm{e}}$ is the elastic part of the strain rate, $\dot{\varepsilon}^{\text {vis }}$ is the viscous part of the strain rate, $\kappa^{0}$ is the oedometric swelling coefficient, and $\sigma$ is the current stress. Equation (13) can be integrated as

$$
\Delta \varepsilon^{\mathrm{vis}}=\kappa^{0} \ln \left(\sigma_{0}^{\prime} / \sigma^{\prime}\right) \quad \text { or } \quad \kappa^{0}=\frac{\Delta \varepsilon^{\mathrm{vis}}}{\ln \left(\sigma_{0}^{\prime} / \sigma^{\prime}\right)}
$$

$\kappa^{0}$ is calculated by inserting the evaluated viscous strain from a separate creep test and the stress change from a corresponding relaxation test into eq. (14). Because of the high stiffness or small swelling coefficient $\kappa^{0}$, a small change of the viscous strains results in a large stress change.

To verify this approach, the swelling coefficients of the tests presented in Fig. 4 were determined and compared to swelling coefficients calculated with eq. (14) by inserting the viscous strains from creep phases as well as the respective stress changes in relaxation phases. To this end the viscous strains $\varepsilon^{\text {vis }}$ and the stress change due to relaxation $\left(\sigma_{0}-\sigma\right)$ were evaluated in the same time interval from 1.0 to $864 \mathrm{~s}$ after load change and after setting the strain rate to zero, respectively. The time interval was deliberately chosen and can be arbitrarily changed. The ratios of $\kappa^{0}$ from unloading to $\kappa^{0}$ from eq. (14) lie between 0.79 and 0.95 , which indicates their similarity and that the stress relaxation indeed depends on the unloading stiffness, thus creep and relaxation are actually linked as well for granular soils. Further comparison with additional test data are necessary to confirm this.

\section{Approach for modelling viscous behaviour of sand}

Approaches to model the viscous behaviour of granular soils were already proposed by Tatsuoka et al. (2002), Di Benedetto et al. (2002), Gudehus (2006) or Tatsuoka et al. (2008). They focus on the prediction of the temporary strain rate effect observed in granular soils after a sudden change of the strain rate.

Models describing the viscous behaviour of fine-grained soils are commonly based on Norton's power law (Norton 1929) and the isotache concept by Šuklje (1957), for example the soft soil creep model by Vermeer and Neher (1999) or the viscohypoplastic models by Niemunis (2002) and Gudehus (2004). They use the overconsolidation ratio (OCR) definition by Hvorslev (1960) as the main state variable controlling the effect of viscosity

(15) $\quad$ OCR $=\frac{p_{\mathrm{e}}^{\prime}}{p^{\prime}}$

where $p_{\mathrm{e}}^{\prime}$ is the equivalent effective mean stress on the reference compression line (RCL) and $p^{\prime}$ is the current effective mean stress. A prerequisite for the applicability of these relationships is the existence of a unique RCL where OCR $=1.0$ and which defines the equivalent pressure $p_{\mathrm{e}}^{\prime}$ as a function of the void ratio for a reference strain rate. The uniqueness of the $p_{\mathrm{e}}^{\prime}-e$ relationship is, however, not given for granular soils as will be explained in the following.

Let us first consider the isotropic loading of a fine-grained soil, following the compression law of eq. (1). As it can be schematically seen in Fig. 15a, a state below the RCL, the void ratio $\left(e_{i}\right)$ can be reached by loading, unloading $\left(\rightarrow 1^{\prime} \rightarrow 2\right)$, and by creep $(\rightarrow 1 \rightarrow 2)$ from a certain pressure level. In either case, the soil would be overconsolidated $(\mathrm{OCR}>1)$ at state 2 . Upon isotropic reloading, the soil will remain in an overconsolidated state and behave stiffer until it reaches the RCL $\left(2 \rightarrow 1^{\prime}\right)$. When further loaded at constant volumetric strain rate, the soil will remain on the RCL $\left(1^{\prime} \rightarrow 3\right)$.

The behaviour of a granular soil follows the compression law given by eq. (3) (see Fig. 15b). A state below a RCL defined by an initial void ratio of $e_{i 0}$ and eq. (3) can be reached either by loading, 
Fig. 15. Idealized compressive behaviour of $(a)$ fine-grained and $(b)$ granular soil after creep $(1 \rightarrow 2)$ or unloading $\left(1^{\prime} \rightarrow 2\right)$ as well as compression and creep of $(c)$ granular soil from different initial densities $\left(1 / 1^{\prime} \rightarrow 2 / 2^{\prime} \rightarrow 3 / 3^{\prime}\right)$.

(a)

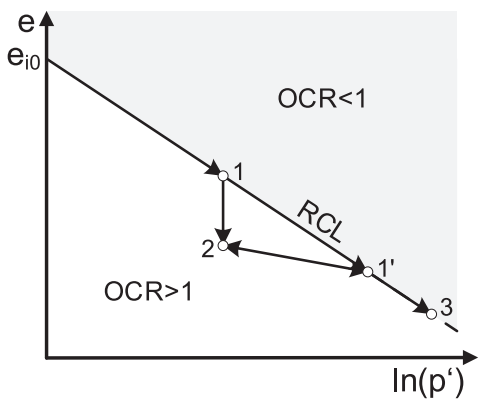

(b)

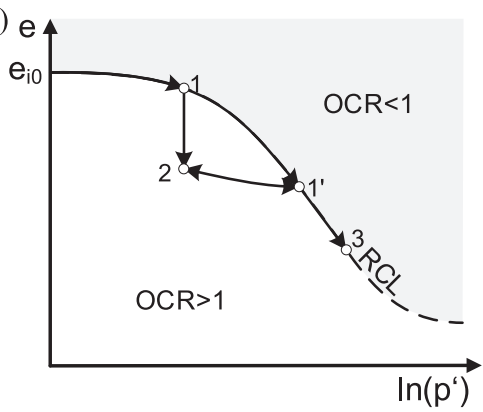

unloading $\left(\rightarrow 1^{\prime} \rightarrow 2\right)$ or creep $(\rightarrow 1 \rightarrow 2)$ as drawn in Fig. 15b. The granular soil at point 2 would be overconsolidated, as a finegrained soil is, see Fig. 15a. Upon reloading according to Figs. 15a and $15 b$, the soil behaviour would be stiffer until stress reaches point $1^{\prime}$ and by further loading, the granular soil state would move along the RCL as given by Fig. $15 b$ in the same way as the finegrained soil (Fig. 15a).

On the contrary, if a granular soil is being compressed from a denser state at $e_{0}^{*}$, where $e_{0}^{*}$ is the void ratio at nearly zero effective mean stress in the denser state, as displayed in Fig. $15 c$, it will reach the point $1^{\prime}$ along the RCL*$^{*}$, unlike a fine-grained soil, without a creep or unloading processes. From point $1^{\prime}$, after a creep phase $\left(1^{\prime} \rightarrow 2^{\prime}\right)$, the granular soil will approach the RCL* upon further loading $\left(2^{\prime} \rightarrow 3^{\prime}\right)$. Clearly, the RCL cannot be unique in granular soils, but depends strongly on the initial density of the soil. This is confirmed by the experimental results presented in this study and results from other researchers (e.g., Bauer 1992; Yamamuro et al. 1996; Herle and Gudehus 1999). The dependency of the compression curve on the initial density is also a very important assumption used in the framework of hypoplasticity (Gudehus 1996). In the following, a concept for the consideration of variable RCLs (RCL*) dependent on the initial void ratio for modelling oedometric and isotropic compression of granular soils including creep is presented.

In the $e-\ln \left(p^{\prime}\right)$ plane the compressive behaviour of granular soils can be described by a band of compression curves as exemplarily shown in Fig. 16, that can be mathematically defined for instance by eq. (3). Each of these curves can be considered as a RCL depending on the initial state of the soil. As shown in Fig. 15c, the reference line changes from RCL at point 1 to RCL* at point $1^{\prime}$, if the compression starts from a denser initial state $e_{0}^{*}$. Knowing the initial value of the three variables OCR, void ratio, and effective pressure the RCL can be determined and the compressive and creep behaviour can be simulated in the framework of the isotache concept. We consider a one-dimensional case of compression and split the strain rate into an (nonlinear) elastic and a plastic part treating all irreversible strains as viscous

$$
\dot{\varepsilon}=\dot{\varepsilon}^{\mathrm{e}}+\dot{\varepsilon}^{\mathrm{vis}}
$$

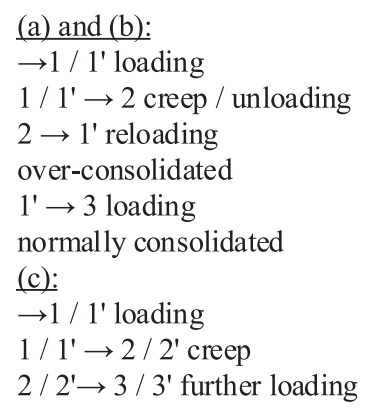

(c)

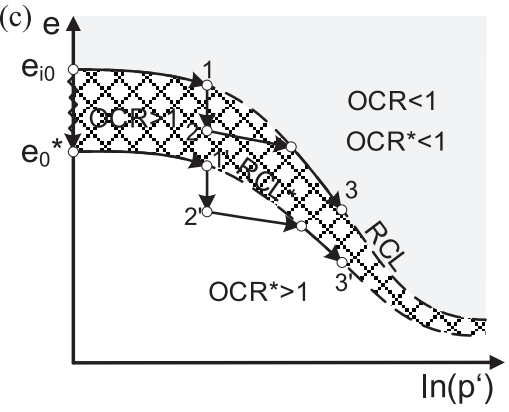

Fig. 16. Oedometric compression test of medium sand (MS) starting from different initial densities and assumed curves for the loosest $e_{i}$ and densest state $e_{\mathrm{d}}$.

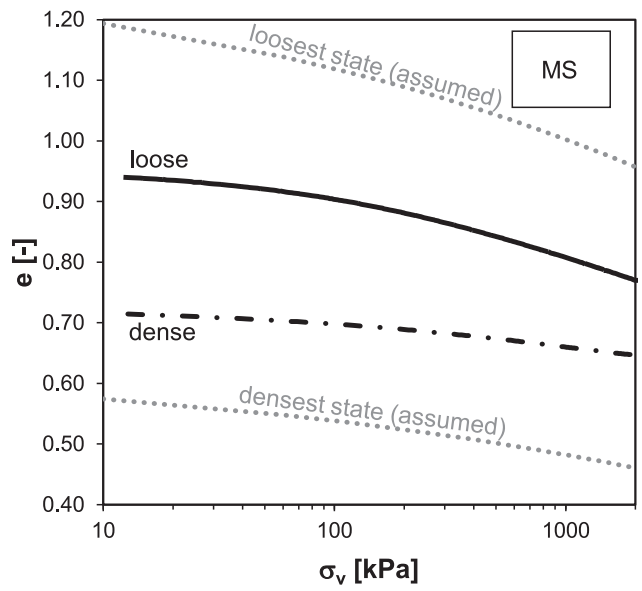

The stress rate can be determined via

$$
\dot{\sigma}^{\prime}=\frac{\sigma^{\prime}}{\kappa}\left(\dot{\varepsilon}-\dot{\varepsilon}^{\mathrm{vis}}\right)
$$

where $\kappa$ is a swelling coefficient, which in granular soils depends on the void ratio and the pressure $p^{\prime}$. The viscous strain rate $\dot{\varepsilon}^{\text {vis }}$ can be calculated by the approach presented by Norton (1929), depending on a reference strain rate $\dot{\varepsilon}_{\mathrm{r}}$ corresponding to the RCL, OCR, and a density- and pressure-dependent viscosity index $I_{\mathrm{v}}=$ $f\left(e, p^{\prime}\right)$ (see Figs. $6 a, 6 b$, and $6 c$ ). The following equation for calculating $\dot{\varepsilon}^{\text {vis }}$ is suggested (Gudehus 2004):

$$
\dot{\varepsilon}^{\text {vis }}=\dot{\varepsilon}_{\mathrm{r}} \exp \left[\frac{\left(p^{\prime} / p_{\mathrm{e}}^{\prime}\right)-1}{I_{\mathrm{v}}}\right]
$$

The determination of the equivalent mean effective stress $p_{\mathrm{e}}^{\prime}$ for granular soils follows eq. (3) with 
Fig. 17. Simulation of a CRS test including creep phases on medium dense sand MS: $(a)$ axial strain over stress in logarithmic scale and (b) axial strain over time in logarithmic scale. Calculated with $h_{\mathrm{s}}=1.6 \cdot 10^{-6} \mathrm{kPa}, n=0.285, p_{\mathrm{ref}}^{\prime}=300 \mathrm{kPa}, C_{\alpha, \mathrm{ref}}\left(r_{\mathrm{e}}=0\right)=10^{-4}, \omega=1.1 \cdot 10^{-3}, \theta=0.3$, $e_{e 0}=0.876, e_{\mathrm{c} 0}=1.09, e_{\mathrm{d} 0}=0.63$.
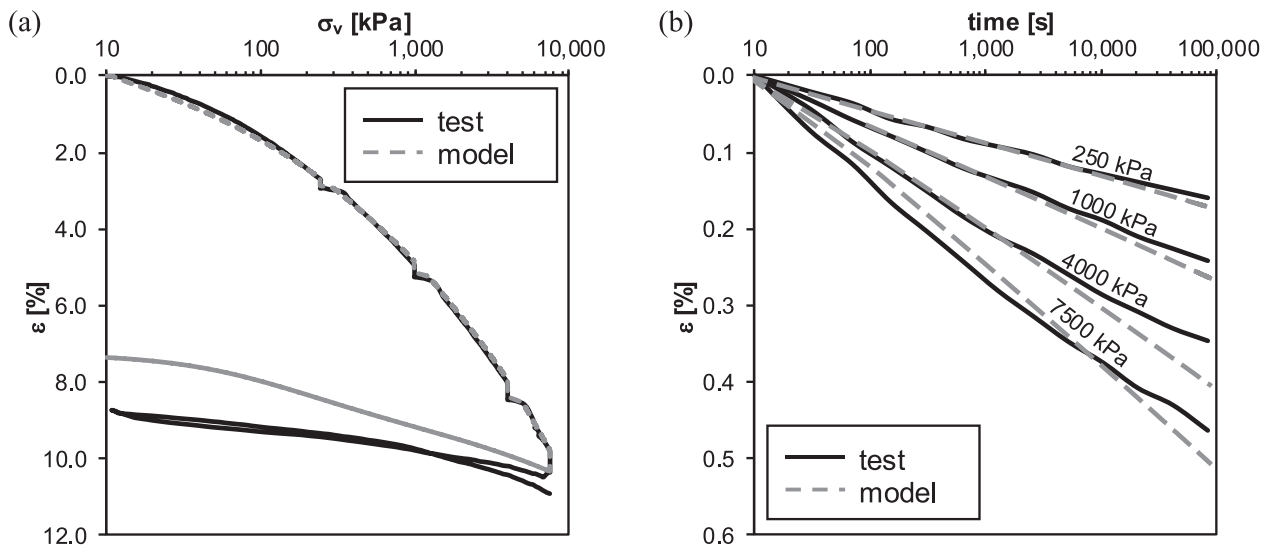

$$
p_{\mathrm{e}}^{\prime}=\frac{1}{3} h_{\mathrm{s}}\left[-\ln \left(e / e_{\mathrm{e} 0}\right)\right]^{1 / n}
$$

where $e_{\mathrm{e} 0}$ is the void ratio for $p^{\prime} \approx 0$ on the RCL. As already mentioned, the three parameters OCR, $p^{\prime}$, and $e$ have to be known to determine the RCL, which depends also on the initial density before compression starts. Equation (19) yields a pressure- and density-dependent compression index $C_{\mathrm{c}}$ as found by experiments (see Fig. 4b):

$$
C_{\mathrm{c}}=e n\left(\frac{p^{\prime}}{h_{\mathrm{s}}}\right)^{n} \ln (10)
$$

The density- and pressure-dependent viscosity index can be determined taking into account the ratio $C_{\alpha} / C_{\mathrm{c}}$ where in the new approach both parameters are density and pressure dependent.

$$
I_{\mathrm{v}}=\frac{C_{\alpha}=f\left(e, p^{\prime}\right)}{C_{\mathrm{c}}=f\left(e, p^{\prime}\right)}
$$

$C_{\mathrm{c}}$ is calculated from eq. (20) and $C_{\alpha}$ is to be analysed from creep tests. The creep coefficients $C_{\alpha}$ determined from the creep tests presented in this paper (see Fig. $5 e$ ) can be approximated by the following relationships:

$$
\begin{aligned}
\frac{C_{\alpha}}{C_{\alpha, \text { ref }}} & =\left(\frac{p^{\prime}}{p_{\text {ref }}^{\prime}}\right)^{\theta} \\
C_{\alpha, \text { ref }} & =\omega r_{\mathrm{e}}+C_{\alpha, \text { ref }}\left(r_{\mathrm{e}}=0\right)
\end{aligned}
$$

and

$$
r_{\mathrm{e}}=\frac{e-e_{\mathrm{d}}}{e_{\mathrm{c}}-e_{\mathrm{d}}}
$$

To use these relationships, the exponent $\theta$, a reference creep coefficient $C_{\alpha, \text { ref }}$ at the reference pressure $p_{\text {ref }}^{\prime}$ with a density dependency factor $\omega$, and $r_{\mathrm{e}}$ the relative void ratio (Gudehus, 1996), which depends on two pressure dependent limit void ratios $\left(e_{\mathrm{c}}\right.$ and $\left.e_{\mathrm{d}}\right)$, need to be found from experiments. $C_{\alpha, \text { ref }}\left(r_{\mathrm{e}}=0\right)$ is the reference creep coefficient at the densest state. The pressuredependent void ratios $e_{\mathrm{c}}$ and $e_{\mathrm{d}}$ can be determined via eq. (3) by replacing $e_{0}$ with the critical void ratio $e_{\mathrm{co}}$ and the densest void ratio $e_{\mathrm{d} 0}$ close to zero pressure.

With the presented model, it was possible to simulate the pressure dependent creep strains of a CRS-creep test on medium dense sand MS. The $24 \mathrm{~h}$ long lasting creep phases were applied at stresses of 250, 1000, 4000, and $7500 \mathrm{kPa}$ (see Fig. 17).

\section{Conclusion}

Results of oedometric compression tests including creep phases lasting $24 \mathrm{~h}$ upon a stepwise doubling of the vertical stress, strain rate-controlled tests including sudden strain rate changes, and tests including relaxation phases of $1 \mathrm{~h}$ were used to illustrate main features of the time-dependent compressive behaviour of sands and the influence of nonplastic fines. When comparing the results of the MS and the SU2, the conclusions of Enomoto et al. (2009) summarized in Table 1 regarding the influence of particle shape, grading, and particle size on the rate-dependent behaviour can generally be confirmed. We observed that the creep rate in granular soils depends on stress and relative density and the $C_{\alpha} / C_{\mathrm{c}}$ ratio is not a material constant in clean sands, but can be roughly assumed as a constant for sands with high fine content. For clean sands, we found CRS tests show very little strain rate dependency and sudden changes of the strain rate result in only a temporary change of the stress-strain curve. An explanation for the observation that in CRS tests, rate dependency is practically not visible, while sudden changes in the strain rate cause an observable although only temporary - change in the stress-strain curve has still to be found. The rate of stress relaxation of the MS seems to follow an isochronous pattern and appears to be linked to the creep rate via the unloading stiffness as in fine-grained soils. Nevertheless, the observed rate-dependent and creep behaviour cannot be described by the isotache concept. To model the creep behaviour of granular soils during one-dimensional compression, a new approach was derived by results gained from the experiments. For predicting creep strains, it is necessary to consider the overconsolidation ratio of granular soils through a variable RCL that is primarily dependent on the initial density before loading. From this approach viscous strains are not only defined by the stress and overconsolidation ratio as sufficient for the modelling of fine grained soils, but also dependent on the initial density as well as the actual density. Further development of this approach is part of ongoing research.

\section{References}

Bauer, E. 1992. Zum mechanischen Verhalten granularer Stoffe unter vorwiegend oedometrischer Beanspruchung. Ph.D. thesis, Department of Civil Engineering, Geo and Environmental Sciences, Karlsruhe Institute of Technology. 
Bauer, E. 1996. Calibration of a comprehensive hypoplastic model for granular materials. Soils and Foundations, 36(1): 13-26. doi:10.3208/sandf.36.13.

Bowman, E.T., and Soga, K. 2003. Creep, ageing and microstructural change in dense granular materials. Soils and Foundations, 43(4): 107-117. doi:10.3208/ sandf.43.4_107.

Charles-Cruz, C.A., Cousens, T.W., and Stewart, D.I. 2008. Compressibility and creep behaviour of hydraulically placed PFA and mine tailings fills. In Proceedings of the 12th Conference of the International Association for Computer Methods and Advances in Geomechanics, Goa, India, 1-6 October 2008. International Association for Computer Methods and Advances in Geomechanics, pp. 2269-2276

Colliat-Dangus, J.L., Desrues, J., and Foray, P. 1988. Triaxial testing of granular soil under elevated cell pressure. In Advanced triaxial testing of soil and rock, ASTM STP 977, Edited by R.T. Donaghe, R.C. Chaney, and M.L. Silvers. American Society for Testing and Materials, Philadelphia. pp. 290-310.

Cudmani, R., Jörger, R., and Wolski, K. 2011. Sydney, Hafenerweiterung Port Botany: Wirtschaftliche Lösungen für höchste geotechnische Anforderungen. In 7. Hans-Lorenz-Symposium, Berlin, Germany, 2011, pp. 231-250.

Di Benedetto, H., Tatsuoka, F., and Ishihara, M. 2002. Time-dependent shear deformation characteristics of sand and their constitutive modelling. Soils and Foundations, 42(2): 1-22. doi:10.3208/sandf.42.2_1.

DIN. 2016. Geotechnical investigation and testing - Laboratory testing of soil Part 4: Determination of particle size distribution (ISO 17892-4:2016); German version EN ISO 17892-4:2016. Deutsches Institut für Normung (DIN). Beuth, Berlin. [In German.]

Duttine, A., and Tatsuoka, F. 2009. Viscous properties of granular materials having different particle shapes in direct shear. Soils and Foundations, 49(5): 777-796. doi:10.3208/sandf.49.777.

Eber, W. 2006. Measurements on the structural contribution to friction in granular media. Ph.D. thesis, Department of Civil, Geo and Environmental Engineering, Technical University of Munich.

Enomoto, T., Kawabe, S., Tatsuoka, F., Di Benedetto, H., Hayashi, T., and Duttine, A. 2009. Effects of particle characteristics on the viscous properties of granular materials in shear. Soils and Foundations, 49(1): 25-49. doi:10. 3208/sandf.49.25.

Glasstone, S., Laidler, K., and Eyring, H. 1941. The theory of rate processes. McGraw-Hill, New York.

Gudehus, G. 1996. A comprehensive constitutive equation for granular materials. Soils and Foundations, 36(1): 1-12. doi:10.3208/sandf.36.1.

Gudehus, G. 2004. A visco-hypoplastic constitutive relation for soft soils. Soils and Foundations, 44(4): 11-25. doi:10.3208/sandf.44.4_11.

Gudehus, G. 2006. Seismo-hypoplasticity with a granular temperature. Granular Matter, 8(2): 93-102. doi:10.1007/s10035-005-0219-9.

Gudehus, G., and Leinenkugel, H.J. 1978. Fließdruck und Fließbewegung in bindigen Böden: Neue Methoden. In Vorträge der Baugrundtagung, Berlin, Germany, 1978, pp. 411-429.

Herle, I., and Gudehus, G. 1999. Determination of parameters of a hypoplastic constitutive model from properties of grain assemblies. Mechanics of CohesiveFrictional Materials, 4(5): 461-486. doi:10.1002/(SICI)1099-1484(199909)4:5<461:: AID-CFM71>3.0.CO;2-P.

Hvorslev, M. 1960. Physical components of the shear strength of saturated clays. In Proceedings of Research Conference on Shear Strength of Cohesive Soils, Boulder, Colorado, 1960. ASCE, New York, pp. 169-273.

Jardine, R.J., Kuwano, R., Zadravkovic, L., and Thornton, C. 1999. Some fundamental aspects of the pre-failure behaviour of granular soils. In Proceedings of the 2nd International Symposium on Pre-failure Deformation Characteristics of Geomaterials, Torino, Italy, 28-30 September 1999, pp. 1077-1111.

Karimpour, H., and Lade, P.V. 2010. Time effects relate to crushing in sand. Journal of Geotechnical and Geoenvironmental Engineering, 136(9): 12091219. doi:10.1061/(ASCE)GT.1943-5606.0000335.

Klobe, B. 1992. Eindimensionale Kompresssion und Konsolidation und darauf basierende Verfahren zur Setzungsprognose. Ph.D. thesis, Department of Civil Engineering, Geo and Environmental Sciences, Karlsruhe Institute of Technology.

Kothen, H., and Knufinke, H.U. 1990. Restsetzungen auf Neulandflächen. Braunkohle, 10: 24-29.

Krieg, S. 2000. Viskoses Verhalten von Mudden, Seeton und Klei. Ph.D. thesis, Department of Civil Engineering, Geo and Environmental Sciences, Karlsruhe Institute of Technology.

Kuwano, R., and Jardine, R.J. 2002. On measuring creep behaviour in granular materials through triaxial testing. Canadian Geotechnical Journal, 39(5): 1061-1074. doi:10.1139/t02-059.

Kwok, C.Y., and Bolton, M.D. 2013. DEM simulations of soil creep due to particle crushing. Géotechnique, 63(16): 1-12.

Lade, P.V. 2009. Creep, stress relaxation, and rate effects in sand. In Proceedings of the 17th International Conference on Soil. Alexandria, Egypt, 5-9 October 2009. Amsterdam: IOS Press, pp. 264-267.

Lade, P.V., and Karimpour, H. 2014. Stress relaxation behavior in Virginia Beach sand. Canadian Geotechnical Journal, 52(7): 813-835.

Lade, P.V., and Liu, C.-T. 1998. Experimental Study of Drained Creep Behavior of Sand, Journal of Engineering Mechanics, 124(8): 912-920.

Lade, P.V., Liggio, C.D., and Nam, J. 2009. Strain rate, creep, and stress drop-creep experiments on crushed coral sand. Journal of Geotechnical and Geoenvironmental Engineering, 135(7): 941-953. doi:10.1061/(ASCE)GT.1943-5606.0000067.
Lade, P.V., Nam, J., and Liggio, C.D. 2010. Effects of particle crushing in stress drop-relaxation experiments on crushed coral sand. Journal of Geotechnical and Geoenvironmental Engineering, 136(3): 500-509. doi:10.1061/(ASCE)GT. 1943-5606.0000212.

Lange, S. 1986. Building on uncompacted dumps in the Rhenish brown coal area of the Federal Republic of Germany. In Building on marginal and derelict land. Glasgow, Ireland, May 1986, pp. 137-153.

Leinenkugel, H.J. 1976. Deformations- und Festigkeitsverhalten bindiger Erdstoffe; Experimemtelle Ergebnisse und ihre physikalische Deutung. Ph.D. thesis, Department of Civil Engineering, Geo and Environmental Sciences, Karlsruhe Institute of Technology.

Leung, C.F., Lee, F.H., and Yet, N.S. 1996. The role of particle breakage in pile creep in sand. Canadian Geotechnical Journal, 33(6): 888-898. doi:10.1139/t96-119.

Lv, Y., Li, F., Liu, Y., Fan, P., and Wang, M. 2017. Comparative study of coral sand and silica sand in creep under general stress states. Canadian Geotechnical Journal, 54(11): 1601-1611. doi:10.1139/cgj-2016-0295.

McDowell, G.R., and Khan, J.J. 2003. Creep of granular materials. Granular Matter, 5(3): 115-120. doi:10.1007/s10035-003-0142-x.

Mejia, C.A., and Vaid, Y.P. 1988. Time dependent behaviour of sand. In Proceedings of the International conference on Rheology and Soil Mechanics. Elsevier, London, pp. 312-326.

Mesri, G., and Castro, A. 1987. $C_{\alpha}-C_{c}$ concept and $\mathrm{K}_{0}$ during secondary compression. Journal of Geotechnical and Geoenvironmental Engineering, 113(3): 230-247. doi:10.1061/(ASCE)0733-9410(1987)113:3(230).

Mesri, G., and Godlewski, P.M. 1977. Time and stress-compressibility interrelationship. Journal of Geotechnical Engineering, 103(5): 417-430.

Mesri, G., and Vardhanabhuti, B. 2009. Compression of granular materials. Canadian Geotechnical Journal, 46(4): 369-392. doi:10.1139/T08-123.

Mesri, G., Feng, T.W., and Benak, J.M. 1990. Postdensification penetration resistance of clean sands. Journal of Geotechnical Engineering, 116(7): 1095-1115. doi:10.1061/(ASCE)0733-9410(1990)116:7(1095).

Michalowski, R., and Nadukuru, S. 2012. Static fatigue, time effects, and delayed increase in penetration resistance after dynamic compaction of sands. Journal of Geotechnical and Geoenvironmental Engineering, 138(5): 564-574. doi:10. 1061/(ASCE)GT.1943-5606.0000611.

Mitchell, J.K., and Solymar, Z.V. 1984. Time-dependent strength gain in freshly deposited or densified sand. Journal of Geotechnical and Geoenvironmental Engineering, 110(11): 1559-1576. doi:10.1061/(ASCE)0733-9410(1984)110:11(1559).

Niemunis, A. 2002. Extended hypoplastic models for soils. Mittelungen Institut für Grundbau und Bodenmechanik, Heft 34, Ruhr-Universität Bochum.

Norton, F.H. 1929. The creep of steel at high temperatures. McGraw-Hill, New York.

Peng, F., Li, F., Tan, Y., and Kongkitkul, W. 2010. FEM simulation of viscous properties for granular materials considering the loading rate effect. Granular Matter, 12(6): 555-568. doi:10.1007/s10035-010-0194-7.

Pham Van Bang, D., Di Benedetto, H., Duttine, A., and Ezaoui, A. 2007. Viscous behaviour of dry sand. International Journal for Numerical and Analytical Methods in Geomechanics, 31(3): 1631-1658. doi:10.1002/nag.606.

Radjai, F., Jean, M., Moreau, J.J., and Roux, S. 1996. Force distributions in dense two-dimensional granular systems. Physical Review Letters, 77: 274-277. doi: 10.1103/PhysRevLett.77.274.

Schmertmann, J.H. 1991. The mechanical ageing of soils. Journal of Geotechnical Engineering, 117(9): 1288-1330. doi:10.1061/(ASCE)0733-9410(1991)117:9(1288).

Suarez, N.R. 2012. Micromechanical aspects of aging in granular soils. Ph.D. thesis, Department of Civil and Environmental Engineering, Virginia Polytechnic Institute and State University.

Šuklje, L. 1957. The analysis of the consolidation process by the Isotaches Method. In Proceedings of the 4th International Conference on Soil Mechanics and Foundation Engineering, Butterworth, London, 1, pp. 200-206.

Tatsuoka, F. 2007. Inelastic deformation characteristics of geomaterial, Soil Stress-Strain Behavior: Measurement, Modelling and Analysis. In Proceedings of the Geotechnical Symposium, Rome, Italy March 2006, pp. 1-109.

Tatsuoka, F., Ishihara, M., Di Benedetto, H., and Kuwano, R. 2002. Timedependent shear deformation characteristics of geomaterials and their simulation. Soils and Foundations, 42(2): 103-129. doi:10.3208/sandf.42.2_103.

Tatsuoka, F., Di Benedetto, H., Enomoto, T., Kawabe, S., and Kongkitkul, W. 2008. Various viscosity types of geomaterials in shear and their mathematical expression. Soils and Foundations, 48(1): 41-60. doi:10.3208/sandf.48.41.

Taylor, D.W. 1948. Fundamentals of soil mechanics. Wiley, New York.

Terzaghi, K. 1925. Erdbaumechanik auf bodenphysikalischer Grundlage. Franz Deuticke, Leipzig/Wien.

Vermeer, P.A., and Neher, H.P. 1999. A soft soil model that accounts for creep. In Proceedings of the International Symposium "Beyond 2000 in Computational Geotechnics”, Rotterdam: Balkema, 1999, Amsterdam, pp. 249-261.

Vogt, N., Heyer, D., Birle, E., Vogt, S., Dahmen, D., Karcher, C., et al. 2013. Special Aspects for Building a Motorway on a $185 \mathrm{~m}$ Deep Dump. In Proceedings of the 18th International Conference on Soil Mechanics and Geotechnical Engineering, Paris, France, 2013, pp. 1377-1380.

Wang, Y.H., Lau, Y.M., and Gao, Y. 2014. Examining the mechanisms of sand creep using DEM simulations, Granular Matter, 16(5): 733-750.

Yamamuro, J.A., Bopp, P.A., and Lade, P.V. 1996. One-dimensional compression of sands at high pressures. Journal of Geotechnical and Geoenvironmental Engineering, 122(2): 147-154. doi:10.1061/(ASCE)0733-9410(1996)122:2(147). 